\title{
ADHD: Current Concepts and Treatments in Children and Adolescents
}

\author{
Renate Drechsler ${ }^{1}$ Silvia Brem ${ }^{1,2}$ \\ Susanne Walitza1,2,4(1)
}

Address for correspondence Susanne Walitza, MD, MSc, Department of Child and Adolescent Psychiatry and Psychotherapy, University Hospital of Psychiatry Zurich, University of Zurich, Neumünsterallee 9, 8032 ZH, Switzerland (e-mail: Susanne.walitza@puk.zh.ch).

\begin{abstract}
Keyword

- ADHD

- etiology

- treatment

Attention deficit hyperactivity disorder (ADHD) is among the most frequent disorders within child and adolescent psychiatry, with a prevalence of over $5 \%$. Nosological systems, such as the Diagnostic and Statistical Manual of Mental Disorders, 5th edition (DSM-5) and the International Classification of Diseases, editions 10 and 11 (ICD-10/11) continue to define ADHD according to behavioral criteria, based on observation and on informant reports. Despite an overwhelming body of research on ADHD over the last 10 to 20 years, valid neurobiological markers or other objective criteria that may lead to unequivocal diagnostic classification are still lacking. On the contrary, the concept of ADHD seems to have become broader and more heterogeneous. Thus, the diagnosis and treatment of ADHD are still challenging for clinicians, necessitating increased reliance on their expertise and experience. The first part of this review presents an overview of the current definitions of the disorder (DSM-5, ICD-10/11). Furthermore, it discusses more controversial aspects of the construct of ADHD, including the dimensional versus categorical approach, alternative ADHD constructs, and aspects pertaining to epidemiology and prevalence. The second part focuses on comorbidities, on the difficulty of distinguishing between "primary" and "secondary" ADHD for purposes of differential diagnosis, and on clinical diagnostic procedures. In the third and most prominent part, an overview of current neurobiological concepts of ADHD is given, including neuropsychological and neurophysiological researches and summaries of current neuroimaging and genetic studies. Finally, treatment options are reviewed, including a discussion of multimodal, pharmacological, and nonpharmacological interventions and their evidence base.
\end{abstract}

received

August 12, 2019

accepted

November 28, 2019

published online

June 19, 2020
DOI https://doi.org/

10.1055/s-0040-1701658. ISSN 0174-304X.
(C) 2020 Georg Thieme Verlag KG Stuttgart · New York
License terms

(c) (i) 


\section{Introduction}

With a prevalence of over $5 \%$, attention deficit hyperactivity disorder (ADHD) is one of the most frequent disorders within child and adolescent psychiatry. Despite an overwhelming body of research, approximately 20,000 publications have been referenced in PubMed during the past 10 years, assessment and treatment continue to present a challenge for clinicians. ADHD is characterized by the heterogeneity of presentations, which may take opposite forms, by frequent and variable comorbidities and an overlap with other disorders, and by the context-dependency of symptoms, which may or may not become apparent during clinical examination. While the neurobiological and genetic underpinnings of the disorder are beyond dispute, biomarkers or other objective criteria, which could lead to an automatic algorithm for the reliable identification of ADHD in an individual within clinical practice, are still lacking. In contrast to what one might expect after years of intense research, ADHD criteria defined by nosological systems, such as the Diagnostic and Statistical Manual of Mental Disorders, 5th edition (DSM-5) and the International Classification of Diseases, editions 10 and 11 (ICD-10/11) have not become narrower and more specific. Rather, they have become broader, for example, encompassing wider age ranges, thus placing more emphasis on the specialist's expertise and experience. ${ }^{1-3}$

\section{Definitions and Phenomenology}

\section{ADHD According to the DSM-5 and ICD-10/11}

ADHD is defined as a neurodevelopmental disorder. Its diagnostic classification is based on the observation of behavioral symptoms. ADHD according to the DSM- 5 continues to be a diagnosis of exclusion and should not be diagnosed if the behavioral symptoms can be better explained by other mental disorders (e.g., psychotic disorder, mood or anxiety disorder, personality disorder, substance intoxication, or withdrawal). ${ }^{1}$ However, comorbidity with other mental disorders is common.

In the DSM-5, the defining symptoms of ADHD are divided into symptoms of inattention (11 symptoms) and hyperactivity/impulsivity ( 9 symptoms). ${ }^{1}$ The former differentiation between subtypes in the DSM-IV proved to be unstable and to depend on the situational context, on informants, or on maturation, and was therefore replaced by "presentations." Thus, the DSM- 5 distinguishes between different presentations of ADHD: predominantly inattentive (6 or more out of 11 symptoms present), predominantly hyperactive/impulsive ( 6 or more out of 9 symptoms present), and combined presentation (both criteria fulfilled), as well as a partial remission category. Symptoms have to be present in two or more settings before the age of 12 years for at least 6 months and have to reduce or impair social, academic, or occupational functioning. In adolescents over 17 years and in adults, five symptoms per dimension need to be present for diagnosis. ${ }^{1}$ In adults, the use of validated instruments like the Wender Utah rating scale is recommended. ${ }^{5}$

In contrast, the ICD-10 classification distinguishes between hyperkinetic disorder of childhood (with at least six symptoms of inattention and six symptoms of hyperactivity/ impulsivity, present before the age of 6 years) and hyperkinetic conduct disorder, a combination of ADHD symptoms and symptoms of oppositional defiant and conduct disorders (CD). ${ }^{3}$ In the ICD-11 (online release from June 2018, printed release expected 2022), the latter category has been dropped, as has the precise age limit ("onset during the developmental period, typically early to mid-childhood"). Moreover, the ICD-11 distinguishes five ADHD subcategories, which match those of the DSM-5: ADHD combined presentation, ADHD predominantly inattentive presentation, ADHD predominantly hyperactive/impulsive presentation and two residual categories, ADHD other specified and ADHD nonspecified presentation. For diagnosis, behavioral symptoms need to be outside the limits of normal variation expected for the individual's age and level of intellectual functioning. ${ }^{2}$

\section{Overlapping Constructs: Sluggish Cognitive Tempo and Emotional Dysregulation}

Sluggish cognitive tempo (SCT) is a clinical construct characterized by low energy, sleepiness, and absent-mindedness, and is estimated to occur in 39 to $59 \%$ of (adult) individuals with ADHD. ${ }^{6,7}$ The question of whether SCT might constitute a feature of ADHD or a separate construct that overlaps with ADHD inattention symptoms is unresolved. ${ }^{8}$ While current studies indicate that SCT might be distinct and independent from hyperactivity/impulsivity, as well as from inattention dimensions, it remains uncertain whether it should be considered as a separate disorder. ${ }^{8,9}$ Twin studies have revealed a certain overlap between SCT and ADHD, especially with regard to inattention symptoms, but SCT seems to be more strongly related to nonshared environmental factors. ${ }^{10}$

Emotion dysregulation is another associated feature that has been discussed as a possible core component of childhood ADHD, although it is not included in the DSM- 5 criteria. Deficient emotion regulation is more typically part of the symptom definition of other psychopathological disorders, such as oppositional defiant disorder (ODD), CD, or disruptive mood dysregulation disorder (DSM-5; for children up to 8 years). ${ }^{11}$ However, an estimated 50 to $75 \%$ of children with ADHD also present symptoms of emotion dysregulation, for example, anger, irritability, low tolerance for frustration, and outbursts, or sometimes express inappropriate positive emotions. The presence of these symptoms increases the risk for further comorbidities, such as ODD and also for anxiety disorders. ${ }^{12,13}$ For adult ADHD, emotional irritability is a defining symptom according to the Wender Utah criteria, and has been confirmed as a primary ADHD symptom by several studies (e.g., Hirsch et al). $5,14,15$

Whether emotion dysregulation is inherent to ADHD, applies to a subgroup with combined symptoms and a singular neurobiological pathway, or is comorbid with but independent of ADHD, is still a matter of debate (for a description of these three models; Shaw et al ${ }^{13}$ ). Faraone et al ${ }^{12}$ distinguished three ADHD prototypes with regard to deficient emotion regulation: ADHD prototype 1 with high-emotional impulsivity and deficient self-regulation, prototype 2 with low-emotional 
impulsivity and deficient self-regulation, and prototype 3 with high-emotional impulsivity and effective self-regulation. All three prototypes are characterized by an inappropriate intensity of emotional response. While prototypes 1 and 3 build up their responses very quickly, prototype 2 is slower to respond but experiences higher subjective emotional upheaval than is overtly shown in the behavior. Prototypes 1 and 2 both need more time to calm down compared with prototype 3 in which emotional self-regulation capacities are intact.

\section{Dimensional versus Categorical Nature of ADHD}

Recent research on subthreshold ADHD argues in favor of a dimensional rather than categorical understanding of the ADHD construct, as its core symptoms and comorbid features are dimensionally distributed in the population. ${ }^{16-18}$ Subthreshold ADHD is common in the population, with an estimated prevalence of approximately $10 \% .{ }^{19}$ According to Biederman and colleagues, clinically referred children with subthreshold ADHD symptoms show a similar amount of functional deficits and comorbid symptoms to those with full ADHD, but tend to come from higher social-class families with fewer family conflicts, to have fewer perinatal complications, and to be older and female (for the latter two, a confound with DSM-IV criteria cannot be excluded). ${ }^{20}$

\section{Temperament and Personality Approaches to ADHD}

Another approach which is in accordance with a dimensional concept is to analyze ADHD and categorize subtypes according to temperament/personality traits (for a review and the different concepts of temperament see Gomez and Corr $^{21}$ ). Temperament/personality traits are usually defined as neurobiologically based constitutional tendencies, which determine how the individual searches for or reacts to external stimulation and regulates emotion and activity. While temperament traits per se are not pathological, extreme variations or specific combinations of traits may lead to pathological behavior. This approach has been investigated in several studies by Martel and colleagues and Nigg, 22-24 who employed a temperament model comprising three empirically derived domains ${ }^{25,26}$ : (1) negative affect, such as tendencies to react with anger, frustration, or fear; (2) positive affect or surgency which includes overall activity, expression of happiness, and interest in novelty; and (3) effortful control which is related to self-regulation and the control of action. The latter domain shows a strong overlap with the concept of executive function. ${ }^{27}$ In a community sample, early temperamental traits, especially effortful control and activity level, were found to potentially predict later ADHD. ${ }^{28}$ Karalunas et al ${ }^{29,30}$ distinguished three temperament profiles in a sample of children with ADHD: one with normal emotional functioning; one with high surgency, characterized by high levels of positive approach-motivated behaviors and a high-activity level; and one with high negative ("irritable") affect, with the latter showing the strongest, albeit only moderate stability over 2 years. Irritability was not reducible to comorbidity with ODD or $\mathrm{CD}$ and was interpreted as an ADHD subgroup characteristic with predictive validity for an unfavorable outcome. These ADHD temperament types were distinguished by resting-state and peripheral physiological characteristics as measured by functional magnetic resonance imaging (fMRI). ${ }^{29}$

\section{Epidemiology and Prevalence}

While ADHD seems to be a phenomenon that is encountered worldwide, $^{31}$ prevalence rates and reported changes in prevalence are highly variable, depending on country and regions, method, and sample. ${ }^{32}$ A meta-analysis by Polanczyk et $\mathrm{al}^{32}$ yielded a worldwide prevalence rate of $5.8 \%$ in children and adolescents. ${ }^{33}$ In an update published 6 years later, the authors did not find evidence for an increase in prevalence over a time span of 30 years. Other meta-analyses reported slightly higher (e.g., $7.2 \%)^{34}$ or lower prevalence rates, which seems to be attributable to the different criteria adopted for defining ADHD. Prevalence rates in children and adolescents represent averaged values across the full age range, but peak prevalence may be much higher in certain age groups, for example, $13 \%$ in 9 -year-old boys. ${ }^{35}$ Universal ADHD prevalence in adults is estimated to lie at $2.8 \%$, with higher rates in high-income (3.6\%) than in low-income (1.4\%) countries. $^{36}$ True prevalence rates (also called community prevalence, e.g., Sayal et $\mathrm{al}^{37}$ ) should be based on populationbased representative health surveys, that is, the actual base rate of ADHD in the population, in contrast to the administrative base rate, which is related to clinical data collection $\left(\right.$ Taylor $^{38}$ ). Recent reports on the increase in ADHD rates usually refer to administrative rates, drawn from health insurance companies, from the number of clinical referrals for $\mathrm{ADHD},{ }^{39}$ clinical case identification estimates, or from the percentage of children taking stimulant medication (prescription data). Changes in these rates may be influenced by increased awareness, destigmatization, modifications in the defining criteria of ADHD, or altered medical practice. According to a recent U.S. health survey on children and adolescents (4-17 years), in which parents had to indicate whether their child had ever been diagnosed with ADHD, the percentage of diagnoses increased from $6.1 \%$ in 1997 to $10.2 \%$ in 2016. ${ }^{40}$ A representative Danish survey based on health registry, data collected from 1995 to 2010 reported that ADHD incidence rates increased by a factor of approximately 12 (for individuals aged 4-65 years) during this period. Moreover, the gender ratio decreased from 7.5:1 to $3: 1$ at early school age and from 8.1:1 to $1.6: 1$ in adolescents in the same time frame, ${ }^{41,42}$ probably indicating an improved awareness of ADHD symptoms in girls. In other countries, it is assumed that girls are still underdiagnosed. ${ }^{38}$

Population register data show that the use of stimulants for ADHD has increased considerably worldwide. ${ }^{43}$ In most countries, an increase in stimulant medication use has been observed in children since the 1990s (e.g., United Kingdom from $0.15 \%$ in 1992 to $5.1 \%$ in $2012 / 2013),{ }^{44,45}$ but in some European countries, stimulant prescription rates for children and adolescents have remained stable or decreased over the last 5 to 10 years (e.g., Germany). ${ }^{35}$ In the United States, the prescription of methylphenidate peaked in 2012 and has since been slightly decreasing, while the use of amphetamines continues to rise. ${ }^{46}$ 


\section{Comorbidity, Differential Diagnosis, and Clinical Assessment}

\section{Comorbidity}

ADHD is characterized by frequent comorbidity and overlap with other neurodevelopmental and mental disorders of childhood and adolescence. The most frequent comorbidities are learning disorders (reading disorders: $15-50 \%$, ${ }^{4}$ dyscalculia: $5-30 \%,{ }^{47}$ autism spectrum disorder, which since the DSM5 is no longer viewed as an exclusion criterion for ADHD diagnosis: $70-85 \%,{ }^{48,49}$ tic/Tourette's disorder and obsessive compulsive disorder: $20 \%$, and $5 \%,{ }^{50}$ developmental coordination disorder: $30-50 \%{ }^{51}$ depression and anxiety disorders: $0-45 \%,{ }^{52,53}$ and ODD and CD: $27-55 \%{ }^{54}$ ). ADHD increases the risk of substance misuse disorders 1.5 -fold (2.4-fold for smoking) and problematic media use 9.3-fold in adolescence ${ }^{55,56}$ and increases the risk of becoming obese 1.23-fold for adolescent girls. ${ }^{57-59}$ It is also associated with different forms of dysregulated eating in children and adolescents. Enuresis occurs in approximately $17 \%$ of children with $\mathrm{ADHD},{ }^{60}$ and sleep disorders in 25 to $70 \%{ }^{61}$ Frequent neurological comorbidities of ADHD include migraine (about thrice more frequent in ADHD than in typically developing [TD] children $)^{62-64}$ and epilepsy (2.3 to thrice more frequent in ADHD than in TD children). ${ }^{65,66}$ The risk of coexisting ADHD being seen as a comorbid condition and not the primary diagnosis is considerably enhanced in many childhood disorders of different origins. For example, the rate of comorbid ADHD is estimated at 15 to $40 \%{ }^{67,68}$ in children with reading disorders and at 26 to $41 \% 69,70$ in children with mild intellectual dysfunction. While comorbidity in neurodevelopmental disorders may arise from a certain genetic overlap (see details under genetic associations), ADHD symptoms are also present in several disorders with well-known and circumscribed genetic defects, normally not related to ADHD (e.g., neurofibromatosis, Turner's syndrome, and Noonan's syndrome) $)^{71}$ or disorders with nongenetic causes, such as traumatic brain injuries, pre-, peri- or postnatal stroke, or syndromes due to toxic agents, such as fetal alcohol syndrome. Comorbid ADHD is estimated in 20 to $50 \%$ of children with epilepsy, ${ }^{72,73}$ in $43 \%$ of children with fetal alcohol syndrome, ${ }^{74}$ and in $40 \%$ of children with neurofibromatosis I $^{75}$ ADHD is three times more frequent in pretermborn children than in children born at term and four times more frequent in extremely preterm-born children. ${ }^{76}$

\section{Differential Diagnosis, Primary and Secondary ADHD}

A range of medical and psychiatric conditions show symptoms that are also present in primary ADHD. The most important medical conditions which are known to "mimic" ADHD and need to be excluded during the diagnostic process are epilepsy (especially absence epilepsy and rolandic epilepsy), thyroid disorders, sleep disorder, drug interaction, anemia, and leukodystrophy. ${ }^{77,78}$ The most important psychiatric conditions to be excluded are learning disorder, anxiety disorders, and affective disorders, while an adverse home environment also needs to be excluded.

However, the picture is complex, as many differential diagnoses may also occur as comorbidities. For instance, bipolar disorder, which is frequently diagnosed in children and adolescents in the United States but not in Europe, is considered as a differential diagnosis to ADHD, but ADHD has also been found to be a comorbidity of bipolar disorder in 21 to $98 \%$ of cases. $^{79}$ Similarly, absence epilepsy is a differential diagnosis of ADHD but is also considered to be a frequent comorbidity, occurring in 30 to $60 \%$ of children with absence epilepsy. ${ }^{80}$ The prevalence of the ADHD phenotype in benign childhood epilepsy with centrotemporal spikes (rolandic epilepsy) lies at 64 to $65 \%,{ }^{81}$ and is possibly related to the occurrence of febrile convulsions. ${ }^{82}$ The literature often does not draw a clear distinction between an ADHD phenotype, which includes all types of etiologies and causes, and a yet to be specified developmental ADHD "genotype." Some authors use terms, such as "idiopathic" ADHD, ${ }^{83}$ "primary," or "genotypic" $\mathrm{ADHD},{ }^{84}$ in contrast to ADHD of circumscribed origin other than developmental, the latter being referred to as ADHD "phenotype," or "phenocopy," ${ }^{85}$ or "ADHD-like." 86 "Secondary ADHD" usually refers to newly acquired ADHD symptoms arising after a known event or incident, for example, a head trauma or stroke. After early childhood stroke, the ADHD phenotype occurs in 13 to $20 \%$ of cases, and after pediatric traumatic brain injury, ADHD symptoms are observed in 15 to $20 \%$ of children. ${ }^{87}$ Having ADHD considerably increases the risk of suffering a traumatic brain injury, ${ }^{88-90}$ and most studies on secondary ADHD after traumatic brain injury control for or compare with premorbid ADHD (e.g., Ornstein et $\mathrm{al}^{91}$ ). Whether and to what extent "phenotypic" and "genotypic" ADHD need to be distinguished on a phenomenological level is not clear. It is possible that shared neurobiological mechanisms will prevail and that genetic vulnerability and epigenetic factors may play a role in both types. For example, James et $\mathrm{al}^{86}$ compared neurophysiological markers in two groups of adolescents with ADHD, one born very preterm and the other born at term. While the authors found very similar ADHDspecific markers in the two groups, some additional deficits only emerged in the preterm group, indicating more severe impairment. Other examples are rare genetic diseases with known genetic defects, which are often comorbid with ADHD. One may ask whether, for example, ADHD in Turner's syndrome should be considered as a rare genetic ADHD variant and count as genotypic ADHD, or whether it results from a different genetic etiology, with the status of an ADHD phenotype.

\section{Clinical Diagnostic Procedure}

Clinical assessment in children should mainly be based on a clinical interview with parents, including an exploration of the problems, the detailed developmental history of the child including medical or psychiatric antecedents, information on family functioning, peer relationships, and school history. According to the guidelines of the National Institute for Health and Care Excellence (NICE) in the United Kingdom, this may also include information on the mental health of the parents and the family's economic situation. The child's mental state should be assessed, possibly using a standardized semistructured clinical interview containing ADHD assessments (e.g., Kiddie Schedule for Affective Disorders 
and Schizophrenia Present and Lifetime version, DSM-5) $)^{92,93}$ and by observer reports. The exploration should cover behavioral difficulties and strengths in several life contexts, for example, school, peer relationships, and leisure time. The use of informant rating scales, such as Conners' Rating Scales, 3rd edition, ${ }^{94}$ or the Strengths and Difficulties Questionnaire ${ }^{95}$ may be useful, but diagnosis should not be solely based on rating scales (NICE, AWFM ADHD). ${ }^{96,97}$ A further interview should be conducted with the child or adolescent to gain a picture of the patient's perspective on current problems, needs, and goals, even though self-reports are considered less reliable for diagnosis. Information should also be obtained from the school, for example, by face-to-face or telephone contact with the teacher and, if possible, by direct school-based observation. A medical examination should be performed to exclude somatic causes for the behavioral symptoms and to gain an impression of the general physical condition of the patient. Current guidelines do not recommend including objective test procedures (intelligence and neuropsychological tests), neuroimaging, or neurophysiological measures in routine ADHD assessment but do suggest their use as additional tools when questions about cognitive functions, academic problems, coexisting abnormalities in electroencephalography (EEG), or unrecognized neurological conditions arise. After completion of the information gathering, the NICE guidelines recommend a period of "watchful waiting" for up to 10 weeks before delivering a formal diagnosis of ADHD. A younger age of the diagnosed child relative to his/her classmates has to be mentioned as one of the many pitfalls in the assessment of ADHD. It has been shown that the youngest children in a class have the highest probability of being diagnosed with ADHD and of being medicated with stimulants. ${ }^{98}$

There is consensus that the diagnosis of ADHD requires a specialist, that is, a child psychiatrist, a pediatrician, or other appropriately qualified health care professionals with training and expertise in diagnosing ADHD. ${ }^{97}$

\section{Current Neurobiological and Neuropsychological Concepts}

\section{Neuropsychology}

\section{Neuropsychological Pathways and Subgroups}

ADHD is related to multiple underlying neurobiological pathways and heterogeneous neuropsychological (NP) profiles. Twenty-five years ago, ADHD was characterized as a disorder of inhibitory self-control, ${ }^{54}$ and an early dual pathway model distinguished between an inhibitory/executive function pathway and a motivational/delay aversion pathway (also called "cool" and "hot" executive function pathways in later publications), which are related to distinct neurobiological networks. ${ }^{99-101}$ Still, the two systems may also interact. ${ }^{102}$

Since then, other pathways have been added, such as time processing, ${ }^{103}$ but a definitive number of possible pathways is difficult to define. For example, Coghill and colleagues ${ }^{104}$ differentiated six cognitive factors in children with ADHD (working memory, inhibition, delay aversion, decision-making, timing, and response time variability) derived from seven subtests of the Cambridge neuropsychological test automated battery. Attempts to empirically classify patients into subgroups with selective performance profiles departing from comprehensive NP data collection were inconclusive. For example, using delay aversion, working memory, and response-time tasks, Lambek and colleagues ${ }^{105}$ expected to differentiate corresponding performance profile subgroups in children with ADHD. However, their analysis resulted in subgroups differentiated by the severity of impairments, and not by selective profiles. Other empirical studies using latent profile or cluster analysis of NP tasks in large ADHD samples have differentiated three ${ }^{106,107}$ or four ${ }^{108}$ NP profile groups, which all included children with ADHD, as well as TD children, differing in severity but not in the type of profile. This might indicate that the identified NP deficit profiles were not ADHD-specific, but rather reflected characteristic distributions of NP performances, which are also present in the general population, with extreme values in children with ADHD. Some other empirical studies in the search for subgroups, however, identified ADHD-specific performance profiles ("poor cognitive control," 109 "with attentional lapses and fast processing speed"110), among other profiles being shared with TD controls. Obviously, divergent results regarding subgrouping may also be related to differing compilations of tested domains, consequently leading to a limited comparability of these studies.

\section{Which Neuropsychological Functions are Impaired in ADHD and When?}

A meta-analysis conducted in 2005 identified consistent executive function deficits with moderate effect sizes in children with ADHD in terms of response inhibition, vigilance, working memory, and planning. ${ }^{67}$ Since then, a vast number of studies on NP deficits in children with ADHD compared with TD controls have been published. A recent meta-analysis included 34 meta-analyses on neurocognitive profiles in ADHD (all ages) published until 2016, referring to 12 neurocognitive domains. ${ }^{111}$ The authors found that $96 \%$ of all standardized mean differences were positive in favor of the control group. Unweighted effect sizes ranged from 0.35 (set shifting) to 0.66 (reaction time variability). Weighted mean effect sizes above 0.50 were found for working memory (0.54), reaction time variability (0.53), response inhibition (0.52), intelligence/achievement (0.51), and planning/organization (0.51). Effects were larger in children and adolescents than in adults. The other domains comprised vigilance, set shifting, selective attention, reaction time, fluency, decision making, and memory.

Nearly every neuropsychological domain has been found to be significantly impaired in ADHD compared with TD controls, though effect sizes are often small. This includes, for example, altered perception (e.g., increased odor sensitivity ${ }^{112}$; altered sensory profile ${ }^{113}$; impaired yellow/blue color perception, e.g., Banaschewski et $\mathrm{al}^{114}$ for review, see Fuermaier et $\mathrm{al}^{115}$ ), emotional tasks (e.g., facial affect discrimination), ${ }^{116}$ social tasks (e.g., Marton et $\mathrm{al}^{117}$ ), communication, ${ }^{118}$ and 
memory. ${ }^{119}$ Several of the described impairments may be related to deficient top-down cognitive control and strategic deficits, ${ }^{120-122}$ but there is also evidence for basic processing deficits. $^{123}$

\section{Neuropsychological Deficits as Mediators of Gene- Behavior Relations}

A vast amount of research has been devoted to the search for neuropsychological endophenotypes (or intermediate phenotypes) for ADHD, that is, neurobiologically based impairments of NP performance characteristic of the disorder that may also be found in nonaffected close relatives. ADHD neuropsychological endophenotypes are assumed to mediate genetic risk from common genetic variants. ${ }^{124}$ So far, deficits in working memory, reaction-time variability, inhibition, time processing, response preparation, arousal regulation, and others have been identified as probable endophenotypes for ADHD. ${ }^{124-127}$ Genetic studies indicate an association of an ADHD-specific polygenetic general risk score (i.e., the total number of genetic variants that may be associated with ADHD, mostly related to dopaminergic transmission) with working memory deficits and arousal/ alertness, ${ }^{124}$ or with a lower intelligence quotient (IQ) and working memory deficits, ${ }^{128}$ respectively. More specifically, a link of ADHD-specific variants of DAT1 genes with inattention and hyperactivity symptoms seems to be mediated by inhibitory control deficits. ${ }^{129}$

\section{Individual Cognitive Profiles and the Relevance of Cognitive Testing for the Clinical Assessment}

Heterogeneity is found with regard to profiles, as well as with regard to the severity of cognitive impairment in individuals with ADHD, as measured by standardized tests. ADHD does not necessarily come with impaired neuropsychological test performance: about one-third of children with ADHD will not present any clinically relevant impairment, while another one-third shows unstable or partial clinical impairment, and about another one-third performs below average in NP tests. The classic concept of NP impairment, which assumes relative stability over time, possibly does not apply to NP deficits observed in ADHD, or only to a lesser extent. For the larger part, the manifestation of performance deficits may depend on contextual factors, ${ }^{130}$ such as reward, or specifically its timing, amount, and nature, or on energetic factors, ${ }^{131}$ for example, the rate of stimulus presentation or the activation provided by the task.

Many studies have shown that behavioral ratings of ADHD symptoms or questionnaires on executive function deficits are not, or at best weakly, correlated with NP test performance, even when both target the same NP domain. ${ }^{132,133}$ In consequence, questionnaires on executive functioning are not an appropriate replacement for neuropsychological testing. Likewise, ADHD symptom rating scales do not predict results of objective attention or executive function tests and vice versa. Although mild intellectual disability and low IQ are more typically associated with the disorder, ADHD can be encountered across the entire IQ spectrum, including highly gifted children. ${ }^{134}$ Therefore, an intelligence test should be part of the diagnostic procedure, but is not mandatory according to ADHD guidelines. In some children, intellectual difficulties and not ADHD may be the underlying cause for ADHD-like behaviors, while in other children with ADHD, academic underachievement despite a high IQ may be present.

It has been argued that symptoms defining ADHD may be understood as dimensional markers of several disorders belonging to an ADHD spectrum and, in consequence, the diagnosis of these behavioral symptoms should be the starting point for a more in-depth diagnosis rather than the endpoint. ${ }^{135}$ This should include the cognitive performance profile. The ADHD behavioral phenotype predicts neither NP impairment nor intellectual achievement in the individual case, and objective testing is the only way to obtain an accurate picture of the child's cognitive performance under standardized conditions. Its goal is not ADHD classification, but rather to obtain the best possible understanding of the relation between cognitive functioning and behavioral symptoms for a given patient, to establish an individually tailored treatment plan.

\section{Neurophysiology}

Neurophysiological methods like EEG, magnetoencephalography, and event-related potentials (ERPs) as task-locked EEG averages capture brain functions in ADHD at high (ms) temporal resolution. The approach covers both fast and slow neural processes and oscillations, and clarifies the type and timing of brain activity altered in ADHD at rest and in tasks. It reveals neural precursors, as well as correlates, and consequences of ADHD behavior. ${ }^{136}$ Neurophysiological and particularly EEG measures also have a long and controversial history as potential biomarkers of ADHD. Current evidence clarifies how multiple pathways and deficits are involved in ADHD at the group level, but recent attempts toward individual clinical translation have also revealed considerable heterogeneity, which does not yet support a clinical application for diagnostic uses or treatment personalization, as explained below.

\section{Resting Electroencephalography}

The EEG is dominated by oscillations in frequency bands ranging from slow $\delta(<4 \mathrm{~Hz})$ and $\theta(4-7 \mathrm{~Hz})$ via $\alpha(8-12 \mathrm{~Hz})$ to faster $\beta(13-30 \mathrm{~Hz})$ and $\gamma(30-100 \mathrm{~Hz})$ band activity. The spectral profile reflects maturation and arousal, with slow frequencies dominating during early childhood and slowwave sleep. Source models can link scalp topography to brain sources and distributed networks.

Initial studies suggested a robust link between ADHD diagnosis and resting EEG markers of reduced attention, hypoarousal, or immaturity, such as increased $\theta$ and an increased $\theta / \beta$ ratio (TBR). However, more recent studies, ${ }^{137,138}$ some with large samples, ${ }^{139,140}$ failed to replicate a consistent TBR increase in ADHD. Instead, the results indicated heterogeneous $\theta$ and $\beta$ power deviations in ADHD not explained by ADHD subtype and psychiatric comorbidity. ${ }^{141}$ A cluster analysis of EEG in children with ADHD also revealed considerable heterogeneity regarding $\theta$ excess and $\beta$ attenuation in ADHD. While several clusters with EEG patterns linked to 
underarousal and immaturity could be identified, only three of the five EEG clusters (60\% of the cases with ADHD) had increased $\theta .{ }^{139}$ Several recent $\theta$ and TBR studies that no longer found TBR association with ADHD diagnosis still replicated the reliable age effects, ${ }^{137,138,142}$ confirming the high quality of these studies. Increasing sleepiness in adolescents, ${ }^{143}$ or shorter EEG recordings, may have reduced the sensitivity to time effects and state regulation deficits in ADHD, ${ }^{136,144}$ potentially contributing to these replication failures. Also, conceptualizing TBR as a marker of inattention or maturational lag may be too simple, since $\theta$ activity can also reflect concentration, cognitive effort, and activation. ${ }^{145,146}$

During sleep, stage profiles reveal no consistent deviations in ADHD, but the slow-wave sleep topography is altered. In particular, frontal slow waves are reduced, leading to a more posterior topography as observed also in younger children. ${ }^{147}$ This delayed frontalization can be interpreted as a maturational delay in ADHD, in line with a cluster of resting EEG, changes in task related ERPs during response inhibition, ${ }^{148}$ and structural magnetic resonance imaging (MRI) findings. ${ }^{149}$

\section{Task Related Event-Related Potentials}

Task-related processing measures, particularly ERPs, have critically advanced our understanding of ADHD through their high-time resolution, which can separate intact and compromised brain functions. ERPs have revealed impairments during preparation, attention, inhibition, action control, as well as error, and reward processing, with partly distinct networks but often present during different phases of the same task. In youth and adults with ADHD, the attentional and inhibitory P3 components and the preparatory contingent negative variation (CNV) component are most consistently affected, but state regulation and error or reward processing are also compromised. ${ }^{136,150}$ Activity during preparation, attention, or inhibition is typically weaker and more variable but not delayed. This often occurs in task phases without visible behavior and precedes the compromised performance. Familial and genetic factors also modulate these markers of attention and control. Some impairment is also observed in nonaffected siblings or in parents without ADHD, ${ }^{151,152}$ and genetic correlates often implicate the dopamine system. ${ }^{125}$ Some ERP changes, like the attenuated $\mathrm{CNV}$ during preparation, remain stable throughout maturation, and are also markers of persistent ADHD, while other markers, such as the inhibition related P3, remain attenuated despite clinical remission. ${ }^{148,153}$

Overall, the ERP results confirm attentional, cognitive, and motivational, rather than sensory or motor impairments in ADHD, in line with current psychological and neurobiological models. However, different ERP studies hardly used the same tests and measures, so valid statements regarding classification accuracy and effect size are particularly difficult, ${ }^{154}$ and there is an urgent need for meta-analyses regarding the different ERPs.

\section{Clinical Translation}

Despite published failures to replicate robust TBR based classification of ADHD, a TBR-based EEG test was recently approved by the U.S. Food and Drug Administration to assist ADHD diagnosis. ${ }^{155}$ Although not promoted as a stand-alone test, children with suspected ADHD, and increased TBR were claimed to likely meet full diagnostic criteria for ADHD; while children with suspected ADHD but no TBR increase should undergo further testing, as they were likely to have other disorders better explaining ADHD symptoms (see also DSM-5 exclusionary criterion E).

This multistage diagnostic approach could possibly identify a homogeneous neurophysiological subgroup, but it omits critical elements of careful, guideline-based ADHD diagnostics. Reliability and predictive value of the TBR remain untested, and the increasing evidence for poor validity of TBR renders it unsuitable for stand-alone ADHD diagnosis. Accordingly, the use of TBR as a diagnostic aid was broadly criticized. ${ }^{156,157}$

In sum, the recent literature suggests that neither TBR nor other single EEG or ERP markers are sufficient to diagnose ADHD and are not recommended for clinical routine use, in line with the increasing evidence for heterogeneity in ADHD.

Combining measures across time, frequency, and tasks or states into multivariate patterns may better characterize ADHD. The potential of such approaches is evident in improved classification using machine-learning algorithms based on combinations of EEG measures ${ }^{142}$ or EEG and ERP measures. ${ }^{138,158}$ However, claims of high-classification accuracies up to $95 \%$ (e.g., Mueller et al ${ }^{158}$ ) require further independent replication and validation with larger samples, and plausible mapping to neural systems and mechanisms. Modern pattern classification is particularly sensitive to uncontrolled sample characteristics and needs validation through independent large samples. ${ }^{159}$

Focusing on EEG-based prediction rather than diagnosis may hold more promise for clinical translation, and may utilize the EEG heterogeneity in clinical ADHD samples. For example, early studies on predicting stimulant response suggested that children with altered wave activity, in particular increased TBR, $\theta$ or $\alpha$ slowing, respond well to stimulant medication. However, in recent prospective work with a large sample, TBR was not predictive, and $\alpha$ slowing allowed only limited prediction in a male adolescent subgroup. ${ }^{160}$

Predicting response to intense nonpharmacological treatment is of particular interest given the high costs and time requirements. Promising findings have been reported for one neurofeedback study, where $\alpha$ EEG activity and stronger CNV activity together predicted nearly $30 \%$ of the treatment response. ${ }^{161}$ Still, the lack of independent validation currently allows no clinical application.

In conclusion, neurophysiological measures have clarified a rich set of distinct impairments but also preserved functions which can also serve as markers of persistence or risk. These markers may also contribute in the classification of psychiatric disorders based on neuromarkers (research domain criteria approach). As potential predictors of treatment outcome they may support precision medicine, and proof-ofconcept studies also highlight the potential of multivariate profiling. The findings also demonstrate the challenge with this approach, including notable replication failures, and 
generalizability of most findings remains to be tested. Neurophysiological markers are not ready to serve as tools or aids to reliably diagnose ADHD, or to personalize ADHD treatment in individual patients.

\section{Neuroimaging}

Modern brain imaging techniques have critically contributed to elucidating the etiology of ADHD. While MRI provides detailed insights into the brain microstructure, such as for example gray matter volume, density, cortical thickness, or white matter integrity, fMRI allows insights into brain functions through activation and connectivity measures with high-spatial resolution.

\section{Delayed Maturation and Persistent Alterations in the Brain Microstructure in ADHD}

The brain undergoes pronounced developmental alterations in childhood and adolescence. Gray matter volume and cortical thickness show nonlinear inverted $\mathbf{U}$-shaped trajectories of maturation with a prepubertal increase followed by a subsequent decrease until adulthood while white matter volume progressively increases throughout adolescence and early adulthood in a rather linear way. ${ }^{162-165}$ Large variations of the maturational curves in different brain regions and subregions suggest that phylogenetically older cortical areas mature earlier than the newer cortical regions. Moreover, brain areas associated with more basic motor or sensory functions mature earlier than areas associated with more complex functions including cognitive control or attention. ${ }^{163,164}$ Altered maturation of the cortex for ADHD has been reported for multiple areas and cortical dimensions, ${ }^{166,167}$ mainly in the form of delayed developmental trajectories in ADHD but recently also as persistent reductions, particularly in the frontal cortex. ${ }^{168}$ Such findings speak for delayed maturation in specific areas rather than a global developmental delay of cortical maturation in ADHD. Microstructural alterations in ADHD have been associated with a decreased intracranial volume ${ }^{169}$ and total brain size reduction of around 3 to $5 \% .{ }^{100,168,170}$ In accordance, increasing ADHD symptoms in the general population correlated negatively with the total brain size. ${ }^{171}$ A meta-analysis (Frodl et al) and a recent cross-sectional mega- and meta-analysis (Hoogman et al) indicate that such reductions in brain volume may be due to decreased gray matter volumes in several subcortical structures, such as the accumbens, amygdala, caudate, hippocampus, and putamen but also cortical areas (prefrontal, the parietotemporal cortex) and the cerebellum. ${ }^{170,172-177}$ Effects sizes of subcortical alterations were highest in children with ADHD and the subcortical structures showed a delayed maturation. ${ }^{169}$ Moreover, higher levels of hyperactivity/impulsivity in children were associated with a slower rate of cortical thinning in prefrontal and cingulate regions. ${ }^{167,178}$ Differences in brain microstructure have also been reported in a metaanalysis for white matter integrity as measured with diffusion tensor imaging in tracts subserving the frontostriatal-cerebellar circuits. ${ }^{179}$ To summarize, diverse neuroanatomical alterations in total brain volume and multiple cortical and subcortical dimensions characterize ADHD. These alterations are most pronounced in childhood and suggest a delayed maturation of specific cortical and subcortical areas along with some persistent reductions in frontal areas in a subgroup of ADHD patients with enduring symptoms into adulthood.

\section{Alterations in the Brain Function of Specific Networks in ADHD}

Specific functional networks, mainly those involved in inhibition, attention processes, cognitive control, reward processing, working memory, or during rest have been intensively studied in ADHD using fMRI in the past. Alterations have been reported in the corresponding brain networks and the main findings are summarized below.

\section{Atypical Resting State Connectivity in Children with ADHD}

Resting state examines spontaneous, low frequency fluctuations in the fMRI signal during rest, that is , in absence of any explicit task. ${ }^{180}$ Resting state networks describe multiple brain regions for which the fMRI signal is correlated (functionally connected) at rest, but the same networks may coactivate also during task-based fMRI. ${ }^{181}$ One important resting state network, the so-called default mode network (DMN), comprises brain areas that show higher activation during wakeful rest and deactivations with increasing attentional demands. ${ }^{182,183}$ While the DMN usually shows decreasing activation with increasing attentional demands, the cognitive control network shows an opposite pattern and increases its activation. This inverse correlation of DMN and the cognitive control networks is diminished or absent in children and adults with ADHD and may explain impaired sustained attention through attentional lapses that are mediated by the DMN. ${ }^{181,184-186}$ In addition, a more diffuse pattern of resting state networks connectivity and a delayed functional network development in children with ADHD have been reported. ${ }^{187}$ Finally, atypical connectivity in cognitive and limbic cortico-striato-thalamo-cortical loops of patients with ADHD suggest that the neural substrates may either reside in impaired cognitive network and/or affective, motivational systems. ${ }^{181}$

\section{Altered Processing of Attention and Inhibition in Fronto-basal Ganglia Circuits in ADHD}

Meta-analyses summarizing the findings of functional activation studies report most consistent alterations in brain activation patterns as hypoactivation of the frontoparietal network for executive functions and the ventral attention system for attentional processes in children with ADHD. ${ }^{188-190}$ More specifically, motor or interference inhibition tasks yielded consistent decreases in a (right lateralized) fronto-basal ganglia network comprising supplementary motor area, anterior cingulate gyrus, left putamen, and right caudate in children with ADHD. ${ }^{189,190}$ For tasks targeting attentional processes, decreased activation in a mainly right lateralized dorsolateral fronto-basal ganglia-thalamoparietal network characterized children with ADHD. Depending on the task, hyperactivation can cooccur in partly or distinct cerebellar, cortical, and subcortical regions. ${ }^{188-190}$ 


\section{Altered Reward Processing and Motivation}

Emotion regulation and motivation is mediated by extended orbitomedial and ventromedial frontolimbic networks in the brain. ${ }^{191}$ Abnormal sensitivity to reward seems to be an important factor in the etiology of ADHD as suggested by several models of ADHD, ${ }^{192-194}$ mainly due to a hypofunctioning dopaminergic system. ${ }^{195}$ In accordance, impairments in specific signals that indicate violations of expectations, the so called reward prediction errors (RPE), were shown in the medial prefrontal cortex of adolescents with ADHD during a learning task. ${ }^{196}$ RPE signals are known to be encoded by the dopaminergic system of the brain, and deficient learning and decision making in ADHD may thus be a consequence of impaired RPE processing. ${ }^{196}$ Abnormal activation has also been reported for the ventral striatum during reward anticipation and in other cortical and subcortical structures of the reward circuitry. ${ }^{197}$

\section{Normalization of Atypical Activation and Brain Structural Measures after Treatment}

Stimulant medication and neurofeedback studies have pointed to a certain normalization of dysfunctional activation patterns in critical dorsolateral frontostriatal and orbitofrontostriatal regions along with improvements in ADHD symptoms. ${ }^{198-201}$ Also, brain microstructure, especially the right caudate, has shown some gradual normalization with long-term stimulant treatment. ${ }^{176,190}$

To conclude, a wide range of neuroimaging studies reveal relatively consistent functional deficits in ADHD during executive functions, including inhibitory control, working memory, reward processes, and attention regulation but also during rest. Some of these alterations are more persistent, others are specific to children and may thus represent a developmental delay. Specific treatments showed trends toward a normalization of alterations in brain microstructure and functional networks.

\section{Genetic Associations with ADHD and ADHD Related Traits}

From family studies, as well as twin studies, the heritability for ADHD has been estimated to be between 75 upto $90 \%{ }^{202}$ Moreover, the heritability was found to be similar in males and females and for inattentive and hyperactive-impulsive components of ADHD. ${ }^{202}$ Interestingly, a strong genetic component was also found when the extreme and subthreshold continuous ADHD trait symptoms were assessed in the Swedish twins. ${ }^{19}$ Even over the lifespan, adult ADHD was found to demonstrate high heritability that was not affected by shared environmental effects. ${ }^{203}$ Recently, structural and functional brain connectivity assessed in families affected by ADHD has been shown to have heritable components associated with ADHD. ${ }^{204}$ Similarly, the heritability of ERPs elicited in a Go/No-Go-task measuring response inhibition known to be altered in ADHD, was found to be significantly heritable. ${ }^{205}$

In several studies, ADHD-related traits have also shown significant heritability. For example, in two independent, population based studies, significant single nucleotide poly- morphism heritability estimates were found for attentiondeficit hyperactivity symptoms, externalizing problems, and total problems. ${ }^{206}$ In another study, investigating the two opposite ends of ADHD symptoms, low-extreme ADHD traits were significantly associated with shared environmental factors without significant heritability. ${ }^{207}$ While on the other hand, high-extreme ADHD traits showed significant heritability without shared environmental influences. ${ }^{207}$ A crossdisorder study including 25 brain disorders from genome wide association studies (GWAS) of 265,218 patients and 784,643 controls, including their relationship to 17 phenotypes from 1,191,588 individuals, could demonstrate significant shared heritability. ${ }^{208}$ In particular, ADHD shared common risk variants with bipolar disorder, major depressive disorder, schizophrenia, and with migraine. ${ }^{208}$ Indeed, in general, population-based twin studies suggest that genetic factors are associated with related-population traits for several psychiatric disorders including ADHD. ${ }^{209}$ This suggests that many psychiatric disorders are likely to be a continuous rather than a categorical phenotype.

Though ADHD was found to be highly heritable, the underlying genetic risk factors are still not fully revealed. The current consensus suggests, as in many other psychiatric disorders, a multifactorial polygenic nature of the common disorder. Both common genetic variants studied by hypothesis-driven candidate gene association or by the hypothesis-free GWAS could only reveal the tip of the iceberg. Through the candidate gene approach, only very few findings could show replicable significant association with ADHD, as reported by meta-analysis studies for the dopaminergic, noradrenergic, and serotonergic genes. ${ }^{210,211}$ Several GWAS have been conducted followed by meta-analysis, which again failed reaching genome-wide significant results. ${ }^{212-224}$ However, recently, the first genomewide significance has been reached in a GWAS meta-analysis consisting of over 20,000 ADHD patients and 35,000 controls. ${ }^{225}$ Twelve independent loci were found to significantly associate with ADHD, including genes involved in neurodevelopmental processes, such as FOX2 and DUSP6. ${ }^{225}$ But even in these findings the effect sizes are rather small to be used for diagnostic tools. Therefore, polygenic risk score approaches have emerged as a possible tool to predict ADHD. ${ }^{202}$ Yet this approach needs further investigation now that genome-wide significance has been reached by Demontis et al. ${ }^{225}$ However, at this point, it is not yet possible to exclude that rare SNPs of strong effect may also be responsible (similar to breast cancer) for a small proportion of ADHD cases due to the heterogeneity of symptomatology, illness course, as well as biological marker distribution, as outlined above.

\section{Treatment}

\section{Multimodal Treatment of ADHD}

A variety of national and international guidelines on the assessment and management of ADHD have been published over the last 10 years, not only for clinicians but also for patients and caregivers. ${ }^{96,97,226-228}$ All guidelines recommend a multimodal treatment approach in which psychoeducation forms a cornerstone of the treatment and should 
be offered to all of those receiving an ADHD diagnosis, as well as to their families and caregivers.

According to the NICE Guidelines, the first step is always a planning process for the multimodal treatment with respect to the psychological, behavioral, and occupational or educational needs of the child and his/her family. ${ }^{97}$ This planning phase could be organized as a "round table" with the child, parents, and other caregivers. The following aspects should be taken into account: the severity of ADHD symptoms and impairment, the relative impact of other neurodevelopmental or mental health conditions and how these affect or may affect everyday life (including sleep). In addition, resilience and protective factors, as well as the goals of the child and family, should be considered in the intervention process. The participation of child and parents in the planning and treatment process is more centrally outlined in recent guidelines and is emphasized in detail for the different treatment steps (e.g., NICE and S3 Guidelines). ${ }^{96,97}$ The participation process is not just a one-time dialogue but should rather continue throughout all steps of the treatment process. Benefits and harms of nonpharmacological and pharmacological treatments should be discussed carefully and on the basis of the latest evidence. Preferences and concerns, and the importance of adherence to treatment, should be discussed and taken into account within the treatment process. Patients and their families or caregivers should be reassured, as appropriate that they can revisit decisions about treatments.

Multimodal treatment approaches also advocate a systematic adaptive procedure that combines different treatment modules according to the needs and situation of the patient and family. This may, for instance, include a first stage in which parent counseling is initiated, a second-stage encompassing, for example, individual behavioral therapy for the child, while the parents participate in a parent training program in parallel, followed by a third stage in which stimulant medication is started, etc. ${ }^{229,230}$ Environment-centered interventions aim at the counseling or training of parents or the instruction of teachers at school or preschool. Parent training programs may be administered individually or in groups and have shown positive effects on parenting skills, ADHD behavior, and comorbid conduct problems. ${ }^{231-233}$ Family therapy for ADHD focuses on the ADHD family, with the ADHD patient being a part of the family system with dysfunctional interactional patterns. ${ }^{234}$ School-based interventions may target (1) the conditions in the classroom, for example, by minimizing distractions; (2) the instruction of the teacher, for example, by suggesting more appropriate teaching methods or by promoting peer tutoring; or (3) the student, for example, by improving self-management and social skills, or by helping to cope with stigma. ${ }^{235-237}$

\section{Pharmacological Approaches}

\section{Starting Medication}

All medication for ADHD should only be initiated by a health care professional with training and expertise in diagnosing and managing ADHD. The expert should be familiar with the pharmacokinetic profiles and bioavailability of all the short- and long-acting preparations available for ADHD. The following parameters should be considered before first medication: medical history of the child but possibly also of the parents, current medication, height and weight, baseline pulse and blood pressure, a cardiovascular assessment, and an electrocardiogram if the treatment may affect the QT interval. A cardiology expert opinion should be sought before starting medication for ADHD if there is a history of congenital heart disease, previous cardiac surgery, or a history of sudden death in a first-degree relative under the age of 40 years, or if the blood pressure is consistently above the 95th centile for age and height for children and young people.

\section{Age-Specific Needs}

Treatment recommendations are often based on the specific needs of children, youth, or adults. ${ }^{97,226}$ According to the NICE guidelines ${ }^{97}$ and also pharmacological recommendations (e.g., Walitza and colleagues ${ }^{238,239}$ ), a distinction should also be made between children under 5 years of age or preschool children, and school children. For the younger children (under 5 years of age), parent or career training programs and parent group training programs are always first-line treatments. Medication for children under 5 years with ADHD should only be given following a second specialist opinion from an ADHD service with expertise in managing ADHD in young children (ideally from a tertiary service). For children over 5 years of age, education and information about the causes and impact of ADHD and advice on parenting strategies should be offered, as well as liaison with school, college, or university if consent to do so is provided. ${ }^{97}$ Children aged 5 years and over and young people should only receive medication if the ADHD symptoms are still causing a persistent significant impairment in at least one life domain after environmental modifications have been implemented and evaluated.

\section{Selection of Pharmacotherapy}

In Europe, methylphenidate either as short- or long-acting preparation is the first-line medication for ADHD across the life span. Second-line medications are lisdexamfetamine, atomoxetine, and guanfacine. A switch to lisdexamfetamine is only recommended if children have first undergone at least a 6-week trial of methylphenidate at an adequate dose and have not derived sufficient benefit in terms of reduced ADHD symptoms and associated impairment, or if patients experience adverse side effects. ${ }^{238}$ The Canadian Guidelines (2018) recommend an individual treatment approach, which can start with different options, and if medication is to be used, long-acting formulations of psychostimulants or atomoxetine are always the first choice. ${ }^{226}$ Comorbid disorders may necessitate adjustments to the treatment plan or alternative treatments.

According to the NICE guidelines, atomoxetine and guanfacine should only be offered if patients cannot tolerate methylphenidate or lisdexamfetamine or if their symptoms have not responded to separate 6-week trials of methylphenidate and lisdexamfetamine, having considered alternative preparations and adequate doses. ${ }^{97}$ 


\section{Evidence for ADHD Medications}

In the first "gold standard" study comparing the different treatment approaches for ADHD alone and in combination (National Institute of Mental Health Collaborative Multimodal Treatment Study of Children with ADHD [MTA study]), the effects of both pharmacological therapy (methylphenidate and intensive counseling) and of multimodal therapy (methylphenidate and intensive behavioral therapy) were significantly more effective after 14 months than behavioral therapy alone or than the "standard" therapy (treatment as usual in the community) of the control group. The multimodal therapy was not significantly superior to pharmacological therapy alone, but did result in significant improvements in ADHD symptoms at a lower dosage of methylphenidate. ${ }^{240-242}$ Since the MTA study, numerous studies have investigated methylphenidate, amphetamine, and nonstimulants like atomoxetine or $\alpha_{2}$-adrenoceptor agonists, such as clonidine and guanfacine, regarding different aspects of effectiveness and tolerability.

The psychostimulants methylphenidate and amphetamine are the most effective agents for the treatment of core ADHD symptoms, with a favorable efficacy and adverse event profile. ${ }^{243-245}$ Compared with methylphenidate and amphetamine, which both show immediate symptom reduction, the full effects of atomoxetine and guanfacine on reducing ADHD symptoms usually only unfold after some weeks of administration. Atomoxetine and guanfacine are not controlled substances, and are licensed in various Euro- pean countries and in the United States for treatment of ADHD in children above the age of 6 years. Both have been shown to be effective in decreasing ADHD core symptoms with an effect size of around 0.7, which is somewhat lower than the effect size for methylphenidate, depending on the underlying studies (e.g., Sallee et $\mathrm{al}^{246}$ ).

\section{Management Strategies and Duration of Pharmacological Treatment}

Following an adequate dosage of medication ( - Table $\mathbf{1})$ and treatment response, medication for ADHD should be titrated to an optimized dosage with regard to the clinical efficacy, safety, and side effects, which should be continued for as long as it remains clinically necessary and effective. This should be reviewed at least annually, also with a planned "medication break" to decide whether there is a continuing need for care. $^{238,239}$ However, there is little available empirical evidence to guide clinicians on questions, such as the optimum duration of treatment and when it is appropriate to consider drug discontinuation. As ADHD can persist into adulthood, decisions on treatment discontinuation need to be taken on a case-by-case basis. ${ }^{226}$

Among the most frequent side effects of psychostimulant therapy ( - Table 2 ) are reduced appetite and sleep disturbances. ${ }^{247}$ Appetite reduction following treatment initiation with an ADHD drug often attenuates with time. Reduced appetite at mealtimes can be avoided by taking the medication after meals rather than before. Should a clinically

Table 1 Dosage recommendation for the most commonly used psychostimulants and other medications in the treatment of children and adolescents with ADHD

\begin{tabular}{|c|c|c|c|}
\hline Generic name or trade name & $\begin{array}{l}\text { Dosage } \\
\text { (mg/kg body weight) }\end{array}$ & $\begin{array}{l}\text { Total daily dosages } \\
\text { (mg) }\end{array}$ & Number of doses per day \\
\hline Methylphenidate immediate release & \multirow[t]{2}{*}{$0.3-\max .1 .0$} & $5-40$ & \multirow[t]{2}{*}{$1-3$} \\
\hline Ritalin Medikinet & & Max.: 60 & \\
\hline Methylphenidate sustained release & all preparations: $0.3-1.0$ & & \\
\hline Concerta & & $18-54 \mathrm{mg}$ & 1 \\
\hline Medikinet Retard & & $10-40^{*}$ & 1 \\
\hline Ritalin LA & & $10-40^{*}$ & 1 \\
\hline \multirow[t]{2}{*}{ Amphetamine Liquid } & $0.1-0.5$ & $2.5-20$ & $1-2(3)$ \\
\hline & & $\max .40$ & \\
\hline Lisdexamphetamine & & $30-70$ & 1 \\
\hline Atomoxetine & $0.5-0.8 ; \max .1 .2$ & If less than $70 \mathrm{~kg}:$ & $1-2$ \\
\hline \multirow[t]{2}{*}{ Strattera } & & $18-60$ & \\
\hline & & $\begin{array}{l}\text { if more than } 70 \mathrm{~kg}: \\
40 \text {-max. } 100\end{array}$ & \\
\hline Guanfacine extended release & \multirow[t]{2}{*}{$0.05-0.12$} & \multirow[t]{2}{*}{$1-4$} & \multirow[t]{2}{*}{1} \\
\hline Intuniv & & & \\
\hline
\end{tabular}

Without any reason the dose should not be increased above $60 \mathrm{mg}$.

Abbreviations: ADHD, attention deficit hyperactivity disorder; max. maximum.

Adapted from (1) Walitza S, Romanos M, Greenhill LL, Banaschewski T. Attention-Deficit/Hyperactivity Disorders. In: Gerlach M, Warnke A, Greenhill LL, eds. Psychiatric Drugs in Children and Adolescents. Wien: Springer; 2014:369-381 238 and (2) Walitza S, Gerlach M, Romanos M, Renner T. Psychostimulanzien und andere Arzneistoffe, die zur Behandlung der Aufmerksamkeitsdefizit-/Hyperaktivitätsstörung (ADHS) angewendet werden. In: Gerlach M, Mehler-Wex C, Walitza S, Warnke A, Wewetzer C, eds. Neuro-/Psychopharmaka im Kindes- und Jugendalter: Grundlagen und Therapie. Berlin, Heidelberg: Springer Berlin Heidelberg; 2016:289-331.239 
Table 2 Adverse drug reactions for psychostimulants and other medications in the treatment of children and adolescents with attention deficit hyperactivity disorder

\begin{tabular}{|l|l|}
\hline Generic name & Adverse drug reaction \\
\hline $\begin{array}{l}\text { Methylphenidate } \\
\text { (different methylphenidate } \\
\text { formulations) }\end{array}$ & $\begin{array}{l}\text { decreased appetite, insomnia or sleep disturbance, snoring, non-breathing or gasping while } \\
\text { sleeping, sleepwalking, various sleep positions, enuresis, talking to sleep, number of hours of } \\
\text { sleep, number of nocturnal movements, sleep quality, stomach upset, dizziness, headache, } \\
\text { irritability, nausea, vomiting, tachycardia, increased blood pressure, moodiness, weight loss } \\
\text { (higher dose), psychotic disorder, arrhythmias }\end{array}$ \\
\hline $\begin{array}{l}\text { Amphetamine } \\
\text { (different formulations) }\end{array}$ & $\begin{array}{l}\text { appetite suppression, weight loss, insomnia, stomach aches, headaches, irritability, dizziness, } \\
\text { possible growth inhibition, exacerbation of psychosis, and tics, and possible increase in blood } \\
\text { pressure and pulse }\end{array}$ \\
\hline Atomoxetine & headache, nausea, abdominal pain, decreased appetite, moodiness and somnolence \\
\hline Guanfacine & somnolence, sedation, headache, upper abdominal pain, and fatigue \\
\hline
\end{tabular}

Adapted from (1) Walitza S, Romanos M, Greenhill LL, Banaschewski T. Attention-Deficit/Hyperactivity Disorders. In: Gerlach M, Warnke A, Greenhill LL, eds. Psychiatric Drugs in Children and Adolescents. Wien: Springer; 2014:369-381238; (2) Walitza S, Gerlach M, Romanos M, Renner T. Psychostimulanzien und andere Arzneistoffe, die zur Behandlung der Aufmerksamkeitsdefizit-/Hyperaktivitätsstörung (ADHS) angewendet werden. In: Gerlach M, Mehler-Wex C, Walitza S, Warnke A, Wewetzer C, eds. Neuro-/Psychopharmaka im Kindes- und Jugendalter: Grundlagen und Therapie. Berlin, Heidelberg: Springer Berlin Heidelberg; 2016:289-331 239; (3) Huang YS, Tsai MH. Long-term outcomes with medications for attention-deficit hyperactivity disorder: current status of knowledge. CNS Drugs 2011;25:539-554; (4) Storebo OJ, Pedersen N, Ramstad E et al. Methylphenidate for attention deficit hyperactivity disorder (ADHD) in children and adolescents - assessment of adverse events in non-randomized studies. Cochrane Database Syst Rev 2018;5:CD012069284; and (5) Wigal T, Greenhill L, Chuang S et al. Safety and tolerability of methylphenidate in preschool children with ADHD. J Am Acad Child Adolesc Psychiatry 2006;45:1294-1303.

significant lack of appetite persist, dosage reduction (by onefourth or half tablet of methylphenidate), discontinuation (rarely necessary), or switching to a different formulation or medication should be considered.

\section{Nonpharmacological Treatments}

\section{Cognitive Behavioral Therapy}

Cognitive behavioral therapy (CBT) is a form of behavioral intervention which aims at reducing ADHD behaviors or associated problems by enhancing positive behaviors and creating situations in which desired behaviors may occur. In the case of preschool and young school children, CBT focuses on parents and educators, who are instructed and trained to act according to CBT principles, while older children and adolescents may be trained directly to use more appropriate behavioral strategies. ${ }^{248} \mathrm{CBT}$ and its more specific forms (e. g., social skills training, training of planning and organizational skills, and self-management techniques) have positive effects on behavior, parenting skills, child-parent relationships, and certain daily living skills, ${ }^{232,249}$ although effects on ADHD core symptoms are inconsistent and relatively low when only blinded assessments are considered. ${ }^{250} \mathrm{~A}$ recent meta-analysis suggested that the combined treatment of medication with CBT is more efficacious than stimulant medication alone (with an estimated standardized mean difference of 0.5$)^{251}$

\section{Neuropsychological Treatments}

In cognitive training interventions, either PC-supported or in a manualized format, cognitive exercises that tap into cognitive domains, such as working memory or inhibitory control, are performed in a repetitive manner and with increasing difficulty. The evidence base for this type of intervention is poor according to recent studies (e.g., Bikic et $\mathrm{al}^{252}$ ) and metastudies (e.g., Cortese et $\mathrm{al}^{253}$ ). While some "near-transfer" improvements in neuropsychological tests tapping into the trained domain are probable, the evidence for "far transfer" to academic achievements or to the ADHD symptom level is weak. Most studies, however, used the same kind of cognitive training with all participants, irrespective of their actual individual cognitive difficulties. Moreover, they did not adhere to theoretically based training principles, which recommend domain-specific training for the functional improvement of a selective neuropsychological deficit. Possibly, future approaches that combine repetitive exercise and top-down strategy application may provide larger benefits for children with ADHD.

In neurofeedback training (NF), EEG activity measured by one or more electrodes applied to the head is transformed into a visual or acoustic signal and fed back online, for example, by a stimulus moving up and down. By steering the stimulus on the screen, the participant may gain control over his/her EEG activity. Many different training protocols have been applied to ADHD. Those which have received the best evaluation are the NF training of the $\theta / \beta$ frequency bands ratio (the goal is generally to decrease $\theta$ and to increase $\beta$ frequencies) and the training of slow cortical potentials (learning to intentionally increase and decrease cortical excitability over short periods of time). However, "normalizing" an ADHD-specific deviant EEG pattern can no longer qualify as a meaningful goal, as no characteristic ADHD pattern seems to exist (Loo et al, ${ }^{254}$ see neurophysiology section), although gaining control over one's brain activity and over attentional states continues to be a valid treatment goal. According to parent ratings, clinical improvements after NF are stronger and longer-lasting compared with other behavioral treatment methods, but teacher ratings usually fail to yield significant effects. ${ }^{255}$ Recent research has focused on the specificity of treatment effects, 
defined as the association between the learned regulation of EEG activity and the behavioral outcome. ${ }^{256}$ To date, there is no convincing evidence that the learned control over brain activity is responsible for the observed behavioral improvements. Instead, nonspecific treatment effects, such as improved self-efficacy, positive reinforcement, and learning to sit still, seem to contribute in large part to the positive clinical outcome.

Methodologically more sophisticated NF approaches, such as tomographic $\mathrm{NF}^{257} \mathrm{fMRI-NF},{ }^{258}$ or near-infrared spectroscopy feedback (feedback of hemoglobin oxygenation $)^{259}$ are still in the experimental stage.

\section{Noninvasive Brain Stimulation}

Repetitive transcranial magnetic stimulation (TMS) and transcranial direct current stimulation (tDCS) represent other potential means to modulate cortical activity. Therefore, these approaches may also be promising in terms of improving clinical and cognitive ADHD symptoms such as inattention and impulsiveness. ${ }^{258,260-262}$ Based on a metaanalysis, Westwood et $\mathrm{al}^{263}$ suggested that left and/or right prefrontal stimulation may improve performance in attention, inhibition and/or working memory tasks. However, these approaches are not yet recommended by therapy guidelines.

\section{Alternative Nonpharmacological Treatment Methods}

Mindfulness training, physical activity, and yoga seem to have positive effects on ADHD behavior, but for the time being, the scientific evidence is weak and these treatments are seen at best as complementary to other interventions. ${ }^{264-268}$ Digital home treatment programs or support apps are currently being developed for ADHD patients or their parents ${ }^{269,270}$; their usefulness or clinical validity still needs to be tested. Children and adolescents with ADHD often show a great affinity with digital media, which may improve compliance, but one has to take into account that the rate of problematic internet use and gaming is enhanced in youth with ADHD (estimated at $37 \%$ in ADHD vs. $12 \%$ in TD). ${ }^{271}$ Free fatty acid supplementation has been described to bring about small but significant reductions in ADHD symptoms even with probably blinded assessments (standardized mean difference $=0.16) .{ }^{250}$

\section{Long-Term Outcome}

Follow-up studies have reported divergent results, with some reporting high rates of persistence until adulthood (up to $79 \%$ ), ${ }^{153}$ and others showing much higher rates of remission from childhood to adolescence (e.g., $45-55 \%$ of syndromal remissions). ${ }^{272-274}$ Recent population-based studies from Brazil, the United Kingdom, and New Zealand have claimed that a large portion of de novo ADHD cases emerge at adult age, ${ }^{275-277}$ but these results can probably be explained by methodological artifacts and missed subthreshold cases. ${ }^{76,278,279}$ However, meta-analytic findings by Bonvicini et $\mathrm{al}^{280}$ indicate that in part, different genes and polymorphisms seem to contribute to childhood ADHD and adulthood ADHD, lending some genetic plausibility to findings of a late manifestation of the disorder. According to the MTA study, the contribution of interventions administered during childhood to outcome in adulthood is negligible, but controlled intervention was limited to a relatively short period of time (14 months). ${ }^{281}$ Neurobiologically, the course of ADHD may be explained by different models. ${ }^{274}$ According to the first model, remission at adult age may be reduced to the normalization of brain functions through maturation. A second model explains remission through the recruitment of compensatory brain functions. The third model claims that brain function anomalies show life-long persistence, even though behavioral dysfunction may have remitted. ${ }^{274}$ Possibly, all of these models, and probably additional ones too (see e.g., Doehnert et $\mathrm{al}^{148}$ ), apply to different subgroups of patients or functions and may account for the divergent results in the literature.

\section{Conflict of Interest}

D.B. reports having served as an unpaid scientific advisor for an EU-funded neurofeedback trial unrelated to the present work.

S.W. reports grants from Gertrud Thalmann Fonds of the UPK Basel, Collaborative Project, grants from Ebnet Foundation, grants from Mensia Technologies SA \& EU H2020 SME Instrument, grants from University Medical Center Utrecht \& Stanley Medical Research Institute, Collaborative Project, grants from Swiss National Foundation, Investigator Initiated Clinical Trial, other from Thieme Neuropychopharmakologie des Kindes und Jugendalters, outside the submitted work; and S.W. has received in the last 5 years royalities from Thieme Hogrefe, Kohlhammer, Springer, Beltz. S.W. has received lecture honoraria from Opopharma in the last 5 years. Her work was supported in the last 5 years by the Swiss National Science Foundation (SNF), diff. EU FP7s, HSM Hochspezialisierte Medizin of the Kanton Zurich, Switzerland, Bfarm Germany, ZInEP, Hartmann Müller Stiftung, Olga Mayenfisch, Gertrud Thalmann Fonds. Outside professional activities and interests are declared under the link of the University of Zurich www.uzh.ch/prof/ssl-dir/interessenbindungen/client/web/.

\section{References}

1 American Psychiatric Association. Diagnostic and Statistical Manual of Mental Disorders, Fifth Edition DSM-5TM. Washington, DC: American Psychiatric Publishing; 2013

2 World Health Organization. ICD-11 for mortality and morbidity statistics. Available at: https://icd.who.int/browse11/1-m/en. Accessed May 18, 2019

3 World Health Organization. ICD-10: International Statistical Classification of Diseases and Related Health Problems. 10th Revision. Vol., 2. Geneva: World Health Organization; 2004

4 Willcutt EG, Nigg JT, Pennington BF, et al. Validity of DSM-IV attention deficit/hyperactivity disorder symptom dimensions and subtypes. J Abnorm Psychol 2012;121(04):991-1010

5 Ward MF, Wender PH, Reimherr FW. The Wender Utah rating scale: an aid in the retrospective diagnosis of childhood attention deficit hyperactivity disorder. Am J Psychiatry 1993;150 (06):885-890 
6 Baytunca MB, Inci SB, Ipci M, Kardas B, Bolat GU, Ercan ES. The neurocognitive nature of children with ADHD comorbid sluggish cognitive tempo: Might SCT be a disorder of vigilance? Psychiatry Res 2018;270:967-973

7 Saxbe C, Barkley RA. The second attention disorder? Sluggish cognitive tempo vs. attention-deficit/hyperactivity disorder: update for clinicians. J Psychiatr Pract 2014;20(01):38-49

8 Willcutt EG, Chhabildas N, Kinnear M, et al. The internal and external validity of sluggish cognitive tempo and its relation with DSM-IV ADHD. J Abnorm Child Psychol 2014;42(01):21-35

9 Becker SP, Leopold DR, Burns GL, et al. The internal, external, and diagnostic validity of sluggish cognitive tempo: a meta-analysis and critical review. J Am Acad Child Adolesc Psychiatry 2016;55 (03):163-178

10 Mueller AK, Tucha L, Koerts J, Groen Y, Lange KW, Tucha O. Sluggish cognitive tempo and its neurocognitive, social and emotive correlates: a systematic review of the current literature. J Mol Psychiatry 2014;2(01):5

11 Brotman MA, Kircanski K, Leibenluft E. Irritability in children and adolescents. Annu Rev Clin Psychol 2017;13:317-341

12 Faraone SV, Rostain AL, Blader J, et al. Practitioner Review: Emotional dysregulation in attention-deficit/hyperactivity disorder - implications for clinical recognition and intervention. J Child Psychol Psychiatry 2019;60(02):133-150

13 Shaw P, Stringaris A, Nigg J, Leibenluft E. Emotion dysregulation in attention deficit hyperactivity disorder. Am J Psychiatry 2014; 171(03):276-293

14 Wender PH. Attention-Deficit Hyperactivity Disorder in Adults. New York: Oxford University Press; 1995

15 Hirsch O, Chavanon M, Riechmann E, Christiansen H. Emotional dysregulation is a primary symptom in adult attention-deficit/ hyperactivity disorder (ADHD). J Affect Disord 2018;232:41-47

16 Balázs J, Keresztény A. Subthreshold attention deficit hyperactivity in children and adolescents: a systematic review. Eur Child Adolesc Psychiatry 2014;23(06):393-408

17 Das D, Cherbuin N, Anstey KJ, Easteal S. ADHD symptoms and cognitive abilities in the midlife cohort of the PATH through life study. J Atten Disord 2015;19(05):414-424

18 Norén Selinus E, Molero Y, Lichtenstein P, et al. Subthreshold and threshold attention deficit hyperactivity disorder symptoms in childhood: psychosocial outcomes in adolescence in boys and girls. Acta Psychiatr Scand 2016;134(06):533-545

19 Larsson H, Anckarsater H, Råstam M, Chang Z, Lichtenstein P. Childhood attention-deficit hyperactivity disorder as an extreme of a continuous trait: a quantitative genetic study of 8,500 twin pairs. J Child Psychol Psychiatry 2012;53(01):73-80

20 Biederman J, Fitzgerald M, Kirova AM, Woodworth KY, Biederman I, Faraone SV. Further Evidence of Morbidity and Dysfunction Associated With Subsyndromal ADHD in Clinically Referred Children. J Clin Psychiatry 2018;79(05):17m11870

21 Gomez R, Corr PJ. ADHD and personality: a meta-analytic review. Clin Psychol Rev 2014;34(05):376-388

22 Martel MM, Nigg JT. Child ADHD and personality/temperament traits of reactive and effortful control, resiliency, and emotionality. J Child Psychol Psychiatry 2006;47(11):1175-1183

23 Martel MM, Nigg JT, von Eye A. How do trait dimensions map onto ADHD symptom domains? J Abnorm Child Psychol 2009;37 (03):337-348

24 Nigg JT. Temperament and developmental psychopathology. J Child Psychol Psychiatry 2006;47(3,4):395-422

25 Rothbart MK. Becoming who we are: Temperament and Personality in Development. New York: Guilford Press; 2011

26 Rothbart MK, Derryberry D. Development of individual differences in temperament. In: Lamb ME, Brown AL, eds. Advances in Developmental Psychology. New York, NY: Lawrence Erlbaum Associates; 1981:37-86

27 Drechsler R, Zulauf Logoz M, Walitza S, Steinhausen HC. The relations between temperament, character, and executive func- tions in children with ADHD and clinical controls. J Atten Disord 2018;22(08):764-775

28 Einziger T, Levi L, Zilberman-Hayun Y, et al. Predicting ADHD symptoms in adolescence from early childhood temperament traits. J Abnorm Child Psychol 2018;46(02):265-276

29 Karalunas SL, Fair D, Musser ED, Aykes K, Iyer SP, Nigg JT. Subtyping attention-deficit/hyperactivity disorder using temperament dimensions: toward biologically based nosologic criteria. JAMA Psychiatry 2014;71(09):1015-1024

30 Karalunas SL, Gustafsson HC, Fair D, Musser ED, Nigg JT. Do we need an irritable subtype of ADHD? Replication and extension of a promising temperament profile approach to ADHD subtyping. Psychol Assess 2019;31(02):236-247

31 Polanczyk GV, Salum GA, Sugaya LS, Caye A, Rohde LA. Annual research review: A meta-analysis of the worldwide prevalence of mental disorders in children and adolescents. J Child Psychol Psychiatry 2015;56(03):345-365

32 Polanczyk GV, Willcutt EG, Salum GA, Kieling C, Rohde LA. ADHD prevalence estimates across three decades: an updated systematic review and meta-regression analysis. Int J Epidemiol 2014; 43(02):434-442

33 Polanczyk G, de Lima MS, Horta BL, Biederman J, Rohde LA. The worldwide prevalence of ADHD: a systematic review and metaregression analysis. Am J Psychiatry 2007;164(06):942-948

34 Thomas R, Sanders S, Doust J, Beller E, Glasziou P. Prevalence of attention-deficit/hyperactivity disorder: a systematic review and meta-analysis. Pediatrics 2015;135(04):e994-e1001

35 Bachmann CJ, Philipsen A, Hoffmann F. ADHD in Germany: trends in diagnosis and pharmacotherapy. Dtsch Arztebl Int 2017;114(09):141-148

36 Fayyad J, Sampson NA, Hwang I, et al; WHO World Mental Health Survey Collaborators. The descriptive epidemiology of DSM-IV Adult ADHD in the World Health Organization World Mental Health Surveys. Atten Defic Hyperact Disord 2017;9(01):47-65

37 Sayal K, Prasad V, Daley D, Ford T, Coghill D. ADHD in children and young people: prevalence, care pathways, and service provision. Lancet Psychiatry 2018;5(02):175-186

38 Taylor E. Attention deficit hyperactivity disorder: overdiagnosed or diagnoses missed? Arch Dis Child 2017;102(04): 376-379

39 Song M, Dieckmann NF, Nigg JT. Addressing discrepancies between ADHD prevalence and case identification estimates among U.S. children utilizing NSCH 2007-2012. J Atten Disord 2019;23(14):1691-1702

40 Xu G, Strathearn L, Liu B, Yang B, Bao W. Twenty-year trends in diagnosed attention-deficit/hyperactivity disorder among US children and adolescents, 1997-2016. JAMA Netw Open 2018; 1(04):e181471

41 Mohr Jensen C, Steinhausen HC. Time trends in incidence rates of diagnosed attention-deficit/hyperactivity disorder across 16 years in a nationwide Danish registry study. J Clin Psychiatry 2015;76 (03):e334-e341

42 Steinhausen HC, Döpfner M, Schubert I. [Time trends in the frequencies of ADHD and stimulant medication]. Z Kinder Jugendpsychiatr Psychother 2016;44(04):275-284

43 Raman SR, Man KKC, Bahmanyar S, et al. Trends in attentiondeficit hyperactivity disorder medication use: a retrospective observational study using population-based databases. Lancet Psychiatry 2018;5(10):824-835

44 Bachmann CJ, Wijlaars LP, Kalverdijk LJ, et al. Trends in ADHD medication use in children and adolescents in five western countries, 2005-2012. Eur Neuropsychopharmacol 2017;27(05):484-493

45 Beau-Lejdstrom R, Douglas I, Evans SJ, Smeeth L. Latest trends in ADHD drug prescribing patterns in children in the UK: prevalence, incidence and persistence. BMJ Open 2016;6(06):e010508

46 Piper BJ, Ogden CL, Simoyan OM, et al. Trends in use of prescription stimulants in the United States and Territories, 2006 to 2016. PLoS One 2018;13(11):e0206100 
47 DuPaul GJ, Gormley MJ, Laracy SD. Comorbidity of LD and ADHD: implications of DSM-5 for assessment and treatment. J Learn Disabil 2013;46(01):43-51

48 Abdallah MW, Greaves-Lord K, Grove J, Nørgaard-Pedersen B, Hougaard DM, Mortensen EL. Psychiatric comorbidities in autism spectrum disorders: findings from a Danish Historic Birth Cohort. Eur Child Adolesc Psychiatry 2011;20(11-12):599-601

49 Simonoff E, Pickles A, Charman T, Chandler S, Loucas T, Baird G. Psychiatric disorders in children with autism spectrum disorders: prevalence, comorbidity, and associated factors in a population-derived sample. J Am Acad Child Adolesc Psychiatry 2008; 47(08):921-929

50 Rothenberger A, Becker A, Brüni LG, Roessner V. Influence of tics and/or obsessive compulsive behaviour on the phenomenology of coexistent ADHD. In: Banaschewski T, Coghill D, Zuddas A, eds. Oxford Textbook of Attention Deficit Hyperactivity Disorder. Oxford: Oxford University Press; 2018:247-253

51 Goulardins JB, Rigoli D, Licari M, et al. Attention deficit hyperactivity disorder and developmental coordination disorder: Two separate disorders or do they share a common etiology. Behav Brain Res 2015;292:484-492

52 Angold A, Costello EJ, Erkanli A. Comorbidity. J Child Psychol Psychiatry 1999;40(01):57-87

53 Meinzer MC, Pettit JW, Viswesvaran C. The co-occurrence of attention-deficit/hyperactivity disorder and unipolar depression in children and adolescents: a meta-analytic review. Clin Psychol Rev 2014;34(08):595-607

54 Barkley RA. ADHD and the Nature of Self-Control. New York, NY: Guilford Press; 2005

55 Charach A, Yeung E, Climans T, Lillie E. Childhood attentiondeficit/hyperactivity disorder and future substance use disorders: comparative meta-analyses. J Am Acad Child Adolesc Psychiatry 2011;50(01):9-21

56 Enagandula R, Singh S, Adgaonkar GW, Subramanyam AA, Kamath RM. Study of Internet addiction in children with attention-deficit hyperactivity disorder and normal control. Ind Psychiatry J 2018;27(01):110-114

57 Aguirre Castaneda RL, Kumar S, Voigt RG, et al. Childhood attention-deficit/hyperactivity disorder, sex, and obesity: a longitudinal population-based study. Mayo Clin Proc 2016;91(03): 352-361

58 Cortese S, Tessari L. Attention-deficit/hyperactivity disorder (ADHD) and obesity: update 2016. Curr Psychiatry Rep 2017; 19(01):4

59 Nigg JT, Johnstone JM, Musser ED, Long HG, Willoughby MT, Shannon J. Attention-deficit/hyperactivity disorder (ADHD) and being overweight/obesity: New data and meta-analysis. Clin Psychol Rev 2016;43:67-79

60 Elia J, Takeda T, Deberardinis R, et al. Nocturnal enuresis: a suggestive endophenotype marker for a subgroup of inattentive attention-deficit/hyperactivity disorder. J Pediatr 2009;155(02): 239-44.e5

61 Tsai MH, Hsu JF, Huang YS. Sleep problems in children with attention deficit/hyperactivity disorder: current status of knowledge and appropriate management. Curr Psychiatry Rep 2016;18(08):76

62 Arruda MA, Arruda R, Guidetti V, Bigal ME. ADHD Is Comorbid to Migraine in Childhood: A Population-Based Study. J Atten Disord 2017; (e-pub ahead of print). Doi: 10.1177/1087054717710767: 1087054717710767

63 Fluegge K, Fluegge K. ADHD and comorbid migraine. Epilepsy Behav 2018;80:378-379

64 Kutuk MO, Tufan AE, Guler G, et al. Migraine and associated comorbidities are three times more frequent in children with ADHD and their mothers. Brain Dev 2018;40(10):857-864

65 Brikell I, Ghirardi L, D'Onofrio BM, et al. Familial liability to epilepsy and attention-deficit/hyperactivity disorder: a nationwide cohort study. Biol Psychiatry 2018;83(02):173-180
66 Socanski D, Aurlien D, Herigstad A, Thomsen PH, Larsen TK. Epilepsy in a large cohort of children diagnosed with attention deficit/hyperactivity disorders (ADHD). Seizure 2013;22(08): 651-655

67 Willcutt EG, Pennington BF, Olson RK, Chhabildas N, Hulslander J. Neuropsychological analyses of comorbidity between reading disability and attention deficit hyperactivity disorder: in search of the common deficit. Dev Neuropsychol 2005;27(01):35-78

68 Willcutt EG. ADHD and reading disorder. In: Banaschewski T, Coghill D, Zuddas A, eds. Oxford Textbook of Attention Deficit Hyperactivity Disorder. Oxford: Oxford University Press; 2018: 273-279

69 Dekker MC, Koot HM. DSM-IV disorders in children with borderline to moderate intellectual disability. I: prevalence and impact. J Am Acad Child Adolesc Psychiatry 2003;42(08):915-922

70 Hässler F, Thome J. [Mental retardation and ADHD]. Z Kinder Jugendpsychiatr Psychother 2012;40(02):83-93, quiz 93-94

71 Green T, Naylor PE, Davies W. Attention deficit hyperactivity disorder (ADHD) in phenotypically similar neurogenetic conditions: Turner syndrome and the RASopathies. J Neurodev Disord 2017;9:25

72 Auvin S, Wirrell E, Donald KA, et al. Systematic review of the screening, diagnosis, and management of ADHD in children with epilepsy. Consensus paper of the Task Force on Comorbidities of the ILAE Pediatric Commission. Epilepsia 2018;59(10): 1867-1880

73 Williams AE, Giust JM, Kronenberger WG, Dunn DW. Epilepsy and attention-deficit hyperactivity disorder: links, risks, and challenges. Neuropsychiatr Dis Treat 2016;12:287-296

74 Banerji A, Shah C. Ten-year experience of fetal alcohol spectrum disorder; diagnostic and resource challenges in Indigenous children. Paediatr Child Health 2017;22(03):143-147

75 Hirabaru K, Matsuo M. Neurological comorbidity in children with neurofibromatosis type 1. Pediatr Int (Roma) 2018;60(01): 70-75

76 Franz AP, Bolat GU, Bolat H, et al. Attention-deficit/hyperactivity disorder and very preterm/very low birth weight: a metaanalysis. Pediatrics 2018;141(01):141

77 Coghill D, Danckaerts M. Organizing and delivering treatment for ADHD. In: Banaschewski T, Coghill D, Zuddas A, eds. Oxford Textbook of Attention Deficit Hyperactivity Disorder. Oxford: Oxford University Press; 2018:417-425

78 Pearl PL, Weiss RE, Stein MA. Medical mimics. Medical and neurological conditions simulating ADHD. Ann N Y Acad Sci 2001;931:97-112

79 Donfrancesco R, Di Trani M, Andriola E, et al. Bipolar disorder in children with adhd: a clinical sample study. J Atten Disord 2017; 21(09):715-720

80 Caplan R, Siddarth P, Stahl L, et al. Childhood absence epilepsy: behavioral, cognitive, and linguistic comorbidities. Epilepsia 2008;49(11):1838-1846

81 Kim EH, Yum MS, Kim HW, KoTS. Attention-deficit/hyperactivity disorder and attention impairment in children with benign childhood epilepsy with centrotemporal spikes. Epilepsy Behav 2014;37:54-58

82 Danhofer P, Pejčochová J, Dušek L, Rektor I, Ošlejšková H. The influence of EEG-detected nocturnal centrotemporal discharges on the expression of core symptoms of ADHD in children with benign childhood epilepsy with centrotemporal spikes (BCECTS): A prospective study in a tertiary referral center. Epilepsy Behav 2018;79:75-81

83 Franke B, Michelini G, Asherson P, et al. Live fast, die young? A review on the developmental trajectories of ADHD across the lifespan. Eur Neuropsychopharmacol 2018;28(10):1059-1088

84 Ekinci O, Okuyaz Ç, Erdoğan S, et al. Attention-deficit hyperactivity disorder (ADHD) in epilepsy and primary ADHD: differences in symptom dimensions and quality of life. J Child Neurol 2017;32(14):1083-1091 
85 Romanos M, Schwenck C, Walitza S. [Diagnosis of attentiondeficit hyperactivity disorder in childhood and adolescence]. Nervenarzt 2008;79(07):782-790

86 James SN, Rommel AS, Cheung C, et al. Association of preterm birth with ADHD-like cognitive impairments and additional subtle impairments in attention and arousal malleability. Psychol Med 2018;48(09):1484-1493

87 Max JE, Schachar RJ, Levin HS, et al. Predictors of secondary attention-deficit/hyperactivity disorder in children and adolescents 6 to 24 months after traumatic brain injury. J Am Acad Child Adolesc Psychiatry 2005;44(10):1041-1049

88 Haarbauer-Krupa J, Lee AH, Bitsko RH, Zhang X, KresnowSedacca MJ. Prevalence of parent-reported traumatic brain injury in children and associated health conditions. JAMA Pediatr 2018;172(11):1078-1086

89 Liou YJ, Wei HT, Chen MH, et al. Risk of traumatic brain injury among children, adolescents, and young adults with attentiondeficit hyperactivity disorder in Taiwan. J Adolesc Health 2018; 63(02):233-238

90 Salinas CM, Dean P, LoGalbo A, Dougherty M, Field M, Webbe FM. Attention-deficit hyperactivity disorder status and baseline neurocognitive performance in high school athletes. Appl Neuropsychol Child 2016;5(04):264-272

91 Ornstein TJ, Sagar S, Schachar RJ, et al. Neuropsychological performance of youth with secondary attention-deficit/hyperactivity disorder 6- and 12-months after traumatic brain injury. J Int Neuropsychol Soc 2014;20(10):971-981

92 Kaufman J, Birmaher B, Brent D, et al. Schedule for affective disorders and schizophrenia for school-age children-present and lifetime version (K-SADS-PL): initial reliability and validity data. J Am Acad Child Adolesc Psychiatry 1997;36(07):980-988

93 Kaufman J, Birmaher B, Axelson D, Perepletchikova F, Brent D, Ryan N. K-SADS-PL DSM-5. Pittsburgh: Western Psychiatric Institute and Clinic; 2016

94 Conners CK, Pitkanen J, Rzepa SR. Conners 3rd Edition (Conners 3; Conners 2008). In: Kreutzer JS, DeLuca J, Caplan B, eds. Encyclopedia of Clinical Neuropsychology. New York, NY: Springer New York; 2011:675-678

95 Goodman R. The strengths and difficulties questionnaire: a research note. J Child Psychol Psychiatry 1997;38(05):581-586

96 ADHS bei Kindern, Jugend und Erwachsenenalter. 2017 Available at: https://www.awmf.org/leitlinien/detail/1l/028-045.html. Accessed February 18, 2019

97 National Institute for Health and Care Excellence (NICE). Attention deficit hyperactivity disorder: diagnosis and management (NICE Guideline 87). 2018 Available at: https://www.nice.org.uk/ guidance/ng87. Accessed February 18, 2019

98 Layton TJ, Barnett ML, Hicks TR, Jena AB. Attention deficithyperactivity disorder and month of school enrollment. N Engl J Med 2018;379(22):2122-2130

99 Castellanos FX, Sonuga-Barke EJ, Milham MP, Tannock R. Characterizing cognition in ADHD: beyond executive dysfunction. Trends Cogn Sci 2006;10(03):117-123

100 Castellanos FX, Tannock R. Neuroscience of attention-deficit/ hyperactivity disorder: the search for endophenotypes. Nat Rev Neurosci 2002;3(08):617-628

101 Sonuga-Barke EJ. Psychological heterogeneity in AD/HD-a dual pathway model of behaviour and cognition. Behav Brain Res 2002;130(1,2):29-36

102 Petrovic P, Castellanos FX. Top-Down Dysregulation-From ADHD to Emotional Instability. Front Behav Neurosci 2016;10:70

103 Sonuga-Barke E, Bitsakou P, Thompson M. Beyond the dual pathway model: evidence for the dissociation of timing, inhibitory, and delay-related impairments in attention-deficit/hyperactivity disorder. J Am Acad Child Adolesc Psychiatry 2010;49 (04):345-355

104 Coghill DR, Seth S, Matthews K. A comprehensive assessment of memory, delay aversion, timing, inhibition, decision making and variability in attention deficit hyperactivity disorder: advancing beyond the three-pathway models. Psychol Med 2014;44(09): 1989-2001

105 Lambek R, Sonuga-Barke E, Tannock R, Sørensen AV, Damm D, Thomsen PH. Are there distinct cognitive and motivational subgroups of children with ADHD? Psychol Med 2018;48(10): $1722-1730$

106 Gomez R, Gomez RM, Winther J, Vance A. Latent profile analysis of working memory performance in a sample of children with ADHD. J Abnorm Child Psychol 2014;42(08):1367-1379

107 Roberts BA, Martel MM, Nigg JT. Are there executive dysfunction subtypes within ADHD? J Atten Disord 2017;21(04):284-293

108 Fair DA, Bathula D, Nikolas MA, Nigg JT. Distinct neuropsychological subgroups in typically developing youth inform heterogeneity in children with ADHD. Proc Natl Acad Sci U S A 2012;109 (17):6769-6774

109 van Hulst BM, de Zeeuw P, Durston S. Distinct neuropsychological profiles within ADHD: a latent class analysis of cognitive control, reward sensitivity and timing. Psychol Med 2015;45 (04):735-745

110 Bergwerff CE, Luman M, Weeda WD, Oosterlaan J. Neurocognitive profiles in children with ADHD and their predictive value for functional outcomes. J Atten Disord 2017; (e-pub ahead of print) . Doi: $10.1177 / 1087054716688533: 1087054716688533$

111 Pievsky MA, McGrath RE. The neurocognitive profile of attention-deficit/hyperactivity disorder: a review of meta-analyses. Arch Clin Neuropsychol 2018;33(02):143-157

112 Romanos M, Renner TJ, Schecklmann M, et al. Improved odor sensitivity in attention-deficit/hyperactivity disorder. Biol Psychiatry 2008;64(11):938-940

113 Little LM, Dean E, Tomchek S, Dunn W. Sensory processing patterns in autism, attention deficit hyperactivity disorder, and typical development. Phys Occup Ther Pediatr 2018;38(03):243-254

114 Banaschewski T, Ruppert S, Tannock R, et al. Colour perception in ADHD. J Child Psychol Psychiatry 2006;47(06):568-572

115 Fuermaier ABM, Hüpen P, De Vries SM, et al. Perception in attention deficit hyperactivity disorder. Atten Defic Hyperact Disord 2018;10(01):21-47

116 Da Fonseca D, Seguier V, Santos A, Poinso F, Deruelle C. Emotion understanding in children with ADHD. Child Psychiatry Hum Dev 2009;40(01):111-121

117 Marton I, Wiener J, Rogers M, Moore C, Tannock R. Empathy and social perspective taking in children with attention-deficit/hyperactivity disorder. J Abnorm Child Psychol 2009;37(01):107-118

118 Korrel H, Mueller KL, Silk T, Anderson V, Sciberras E. Research review: language problems in children with attention-deficit hyperactivity disorder - a systematic meta-analytic review. J Child Psychol Psychiatry 2017;58(06):640-654

119 Rhodes SM, Park J, Seth S, Coghill DR. A comprehensive investigation of memory impairment in attention deficit hyperactivity disorder and oppositional defiant disorder. J Child Psychol Psychiatry 2012;53(02):128-137

120 Egeland J, Johansen SN, Ueland T. Do low-effort learning strategies mediate impaired memory in ADHD? J Learn Disabil 2010; 43(05):430-440

121 Lange-Malecki B, Treue S, Rothenberger A, Albrecht B. Cognitive control over visual motion processing - are children with adhd especially compromised? a pilot study of flanker task eventrelated potentials. Front Hum Neurosci 2018;12:491

122 Wells EL, Day TN, Harmon SL, Groves NB, Kofler MJ. Are emotion recognition abilities intact in pediatric ADHD? Emotion 2019;19 (07):1192-1205

123 Salum GA, Sergeant J, Sonuga-Barke E, et al. Specificity of basic information processing and inhibitory control in attention deficit hyperactivity disorder. Psychol Med 2014;44(03): 617-631

124 Nigg JT, Gustafsson HC, Karalunas SL, et al. Working memory and vigilance as multivariate endophenotypes related to common 
genetic risk for attention-deficit/hyperactivity disorder. J Am Acad Child Adolesc Psychiatry 2018;57(03):175-182

125 Albrecht B, Brandeis D, Uebel-von Sandersleben H, et al. Genetics of preparation and response control in ADHD: the role of DRD4 and DAT1. J Child Psychol Psychiatry 2014;55(08): 914-923

126 Kebir O, Joober R. Neuropsychological endophenotypes in attention-deficit/hyperactivity disorder: a review of genetic association studies. Eur Arch Psychiatry Clin Neurosci 2011;261(08): 583-594

127 Pinto R, Asherson P, Ilott N, Cheung CH, Kuntsi J. Testing for the mediating role of endophenotypes using molecular genetic data in a twin study of ADHD traits. Am J Med Genet B Neuropsychiatr Genet 2016;171(07):982-992

128 Martin J, Hamshere ML, Stergiakouli E, O’Donovan MC, Thapar A. Neurocognitive abilities in the general population and composite genetic risk scores for attention-deficit hyperactivity disorder. J Child Psychol Psychiatry 2015;56(06):648-656

129 Kamradt JM, Nigg JT, Friderici KH, Nikolas MA. Neuropsychological performance measures as intermediate phenotypes for attention-deficit/hyperactivity disorder: A multiple mediation analysis. Dev Psychopathol 2017;29(01):259-272

130 Sonuga-Barke EJ, Coghill D. The foundations of next generation attention-deficit/hyperactivity disorder neuropsychology: building on progress during the last 30 years. J Child Psychol Psychiatry 2014;55(12):e1-e5

131 Sergeant J. The cognitive-energetic model: an empirical approach to attention-deficit hyperactivity disorder. Neurosci Biobehav Rev 2000;24(01):7-12

132 Tan A, Delgaty L, Steward K, Bunner M. Performance-based measures and behavioral ratings of executive function in diagnosing attention-deficit/hyperactivity disorder in children. Atten Defic Hyperact Disord 2018;10(04):309-316

133 Toplak ME, Bucciarelli SM, Jain U, Tannock R. Executive functions: performance-based measures and the behavior rating inventory of executive function (BRIEF) in adolescents with attention deficit/hyperactivity disorder (ADHD). Child Neuropsychol 2009;15(01):53-72

134 Rommelse N, Antshel K, Smeets S, et al. High intelligence and the risk of ADHD and other psychopathology. Br J Psychiatry 2017; 211(06):359-364

135 Heidbreder R. ADHD symptomatology is best conceptualized as a spectrum: a dimensional versus unitary approach to diagnosis. Atten Defic Hyperact Disord 2015;7(04):249-269

136 Brandeis D, Loo S, McLoughlin G, Heinrich H, Banaschewski T. Neurophysiology. In: Banaschewski T, Coghill D, Zuddas A, eds. Oxford Textbook of Attention Deficit Hyperactivity Disorder. Oxford: Oxford University Press; 2018:82-93

137 Buyck I, Wiersema JR. Resting electroencephalogram in attention deficit hyperactivity disorder: developmental course and diagnostic value. Psychiatry Res 2014;216(03):391-397

138 Liechti MD, Valko L, Müller UC, et al. Diagnostic value of resting electroencephalogram in attention-deficit/hyperactivity disorder across the lifespan. Brain Topogr 2013;26(01):135-151

139 Clarke AR, Barry RJ, Dupuy FE, et al. Behavioural differences between EEG-defined subgroups of children with attentiondeficit/hyperactivity disorder. Clin Neurophysiol 2011;122 (07):1333-1341

140 Loo SK, Hale TS, Macion J, et al. Cortical activity patterns in ADHD during arousal, activation and sustained attention. Neuropsychologia 2009;47(10):2114-2119

141 Loo SK, Cho A, Hale TS, McGough J, McCracken J, Smalley SL. Characterization of the theta to beta ratio in ADHD: identifying potential sources of heterogeneity. J Atten Disord 2013;17(05): 384-392

142 Poil SS, Bollmann S, Ghisleni C, et al. Age dependent electroencephalographic changes in attention-deficit/hyperactivity disorder (ADHD). Clin Neurophysiol 2014;125(08):1626-1638
143 Arns M, Conners CK, Kraemer HC. A decade of EEG theta/beta ratio research in ADHD: a meta-analysis. J Atten Disord 2013;17 (05):374-383

144 Zhang DW, Johnstone SJ, Li H, et al. Time effects on resting EEG in children with/without ADHD. Brain Topogr 2019;32(02):286-294

145 Klimesch W. EEG alpha and theta oscillations reflect cognitive and memory performance: a review and analysis. Brain Res Brain Res Rev 1999;29(2-3):169-195

146 Skirrow C, McLoughlin G, Banaschewski T, Brandeis D, Kuntsi J, Asherson P. Normalisation of frontal theta activity following methylphenidate treatment in adult attention-deficit/hyperactivity disorder. Eur Neuropsychopharmacol 2015;25(01):85-94

147 Ringli M, Souissi S, Kurth S, Brandeis D, Jenni OG, Huber R. Topography of sleep slow wave activity in children with attention-deficit/hyperactivity disorder. Cortex 2013;49(01):340-347

148 Doehnert M, Brandeis D, Imhof K, Drechsler R, Steinhausen HC. Mapping attention-deficit/hyperactivity disorder from childhood to adolescence-no neurophysiologic evidence for a developmental lag of attention but some for inhibition. Biol Psychiatry 2010;67(07):608-616

149 Shaw P, De Rossi P, Watson B, et al. Mapping the development of the basal ganglia in children with attention-deficit/hyperactivity disorder. J Am Acad Child Adolesc Psychiatry 2014;53(07): 780-9.e11

150 Barry RJ, Johnstone SJ, Clarke AR. A review of electrophysiology in attention-deficit/hyperactivity disorder: II. Event-related potentials. Clin Neurophysiol 2003;114(02):184-198

151 Albrecht B, Brandeis D, Uebel H, et al. Familiality of neural preparation and response control in childhood attention deficithyperactivity disorder. Psychol Med 2013;43(09):1997-2011

152 McLoughlin G, Asherson P, Albrecht B, et al. Cognitiveelectrophysiological indices of attentional and inhibitory processing in adults with ADHD: familial effects. Behav Brain Funct 2011;7:26

153 Cheung CH, Rijsdijk F, McLoughlin G, et al. Cognitive and neurophysiological markers of ADHD persistence and remission. $\mathrm{Br} \mathrm{J}$ Psychiatry 2016;208(06):548-555

154 Gamma A, Kara O. Event-related potentials for diagnosing children and adults with ADHD. J Atten Disord 2016; (e-pub ahead of print) . Doi: $10.1177 / 1087054716631821$

155 Snyder SM, Rugino TA, Hornig M, Stein MA. Integration of an EEG biomarker with a clinician's ADHD evaluation. Brain Behav 2015; 5(04): $\mathrm{e} 00330$

156 Arns M, Loo SK, Sterman MB, et al. Editorial perspective: how should child psychologists and psychiatrists interpret FDA device approval? Caveat emptor. J Child Psychol Psychiatry 2016;57 (05):656-658

157 Gloss D, Varma JK, Pringsheim T, Nuwer MR. Practice advisory: the utility of EEG theta/beta power ratio in ADHD diagnosis: Report of the Guideline Development, Dissemination, and Implementation Subcommittee of the American Academy of Neurology. Neurology 2016;87(22):2375-2379

158 Mueller A, Candrian G, Grane VA, Kropotov JD, Ponomarev VA, Baschera GM. Discriminating between ADHD adults and controls using independent ERP components and a support vector machine: a validation study. Nonlinear Biomed Phys 2011;5:5

159 Pulini AA, Kerr WT, Loo SK, Lenartowicz A. Classification accuracy of neuroimaging biomarkers in attention-deficit/hyperactivity disorder: effects of sample size and circular analysis. Biol Psychiatry Cogn Neurosci Neuroimaging 2019;4(02):108-120

160 Arns M, Vollebregt MA, Palmer D, et al. Electroencephalographic biomarkers as predictors of methylphenidate response in attention-deficit/hyperactivity disorder. Eur Neuropsychopharmacol 2018;28(08):881-891

161 Wangler S, Gevensleben H, Albrecht B, et al. Neurofeedback in children with ADHD: specific event-related potential findings of a randomized controlled trial. Clin Neurophysiol 2011;122(05): 942-950 
162 Giedd JN, Blumenthal J, Jeffries NO, et al. Brain development during childhood and adolescence: a longitudinal MRI study. Nat Neurosci 1999;2(10):861-863

163 Gogtay N, Giedd JN, Lusk L, et al. Dynamic mapping of human cortical development during childhood through early adulthood. Proc Natl Acad Sci U S A 2004;101(21):8174-8179

164 Sowell ER, Peterson BS, Thompson PM, Welcome SE, Henkenius AL, Toga AW. Mapping cortical change across the human life span. Nat Neurosci 2003;6(03):309-315

165 Sowell ER, Trauner DA, Gamst A, Jernigan TL. Development of cortical and subcortical brain structures in childhood and adolescence: a structural MRI study. Dev Med Child Neurol 2002;44 (01):4-16

166 Shaw P, Eckstrand K, Sharp W, et al. Attention-deficit/hyperactivity disorder is characterized by a delay in cortical maturation. Proc Natl Acad Sci U S A 2007;104(49):19649-19654

167 Shaw P, Malek M, Watson B, Sharp W, Evans A, Greenstein D. Development of cortical surface area and gyrification in attention-deficit/hyperactivity disorder. Biol Psychiatry 2012;72(03): 191-197

168 Ambrosino S, de Zeeuw P, Wierenga LM, van Dijk S, Durston S. What can cortical development in attention-deficit/hyperactivity disorder teach us about the early developmental mechanisms involved? Cereb Cortex 2017;27(09):4624-4634

169 Hoogman M, Bralten J, Hibar DP, et al. Subcortical brain volume differences in participants with attention deficit hyperactivity disorder in children and adults: a cross-sectional mega-analysis. Lancet Psychiatry 2017;4(04):310-319

170 Durston S, Hulshoff Pol HE, Schnack HG, et al. Magnetic resonance imaging of boys with attention-deficit/hyperactivity disorder and their unaffected siblings. J Am Acad Child Adolesc Psychiatry 2004;43(03):332-340

171 Hoogman M, Rijpkema M, Janss L, et al. Current self-reported symptoms of attention deficit/hyperactivity disorder are associated with total brain volume in healthy adults. PLoS One 2012;7 (02):e31273

172 Castellanos FX, Lee PP, Sharp W, et al. Developmental trajectories of brain volume abnormalities in children and adolescents with attention-deficit/hyperactivity disorder. JAMA 2002;288(14): 1740-1748

173 Frodl T, Skokauskas N. Meta-analysis of structural MRI studies in children and adults with attention deficit hyperactivity disorder indicates treatment effects. Acta Psychiatr Scand 2012;125(02): 114-126

174 Greven CU, Bralten J, Mennes M, et al. Developmentally stable whole-brain volume reductions and developmentally sensitive caudate and putamen volume alterations in those with attention-deficit/hyperactivity disorder and their unaffected siblings. JAMA Psychiatry 2015;72(05):490-499

175 Huang-Pollock C, Ratcliff R, McKoon G, Shapiro Z, Weigard A, Galloway-Long H. Using the diffusion model to explain cognitive deficits in attention deficit hyperactivity disorder. J Abnorm Child Psychol 2017;45(01):57-68

176 Nakao T, Radua J, Rubia K, Mataix-Cols D. Gray matter volume abnormalities in ADHD: voxel-based meta-analysis exploring the effects of age and stimulant medication. Am J Psychiatry 2011;168(11):1154-1163

177 Valera EM, Faraone SV, Murray KE, Seidman LJ. Meta-analysis of structural imaging findings in attention-deficit/hyperactivity disorder. Biol Psychiatry 2007;61(12):1361-1369

178 Ducharme S, Hudziak JJ, Botteron KN, et al; Brain Development Cooperative Group. Decreased regional cortical thickness and thinning rate are associated with inattention symptoms in healthy children.J Am Acad Child Adolesc Psychiatry 2012;51(01):18-27.e2

179 van Ewijk H, Heslenfeld DJ, Zwiers MP, Buitelaar JK, Oosterlaan J. Diffusion tensor imaging in attention deficit/hyperactivity disorder: a systematic review and meta-analysis. Neurosci Biobehav Rev 2012;36(04):1093-1106
180 Biswal B, Yetkin FZ, Haughton VM, Hyde JS. Functional connectivity in the motor cortex of resting human brain using echoplanar MRI. Magn Reson Med 1995;34(04):537-541

181 Posner J, Park C, Wang Z. Connecting the dots: a review of resting connectivity MRI studies in attention-deficit/hyperactivity disorder. Neuropsychol Rev 2014;24(01):3-15

182 Buckner RL, Andrews-Hanna JR, Schacter DL. The brain's default network: anatomy, function, and relevance to disease. Ann N Y Acad Sci 2008;1124:1-38

183 Raichle ME, Snyder AZ. A default mode of brain function: a brief history of an evolving idea. Neuroimage 2007;37(04):1083-1090, discussion 1097-1099

184 Cao X, Cao Q, Long X, et al. Abnormal resting-state functional connectivity patterns of the putamen in medication-naïve children with attention deficit hyperactivity disorder. Brain Res 2009;1303:195-206

185 Castellanos FX, Margulies DS, Kelly C, et al. Cingulate-precuneus interactions: a new locus of dysfunction in adult attentiondeficit/hyperactivity disorder. Biol Psychiatry 2008;63(03): 332-337

186 Sun L, Cao Q Long X, et al. Abnormal functional connectivity between the anterior cingulate and the default mode network in drug-naïve boys with attention deficit hyperactivity disorder. Psychiatry Res 2012;201(02):120-127

187 Bos DJ, Oranje B, Achterberg M, et al. Structural and functional connectivity in children and adolescents with and without attention deficit/hyperactivity disorder. J Child Psychol Psychiatry 2017;58(07):810-818

188 Cortese S, Kelly C, Chabernaud C, et al. Toward systems neuroscience of ADHD: a meta-analysis of 55 fMRI studies. Am J Psychiatry 2012;169(10):1038-1055

189 Dickstein SG, Bannon K, Castellanos FX, Milham MP. The neural correlates of attention deficit hyperactivity disorder: an ALE metaanalysis. J Child Psychol Psychiatry 2006;47(10):1051-1062

190 Hart H, Radua J, NakaoT, Mataix-Cols D, Rubia K. Meta-analysis of functional magnetic resonance imaging studies of inhibition and attention in attention-deficit/hyperactivity disorder: exploring task-specific, stimulant medication, and age effects. JAMA Psychiatry 2013;70(02):185-198

191 Rubia K. "Cool" inferior frontostriatal dysfunction in attentiondeficit/hyperactivity disorder versus "hot" ventromedial orbitofrontal-limbic dysfunction in conduct disorder: a review. Biol Psychiatry 2011;69(12):e69-e87

192 Sagvolden T, Johansen EB, Aase H, Russell VA. A dynamic developmental theory of attention-deficit/hyperactivity disorder (ADHD) predominantly hyperactive/impulsive and combined subtypes. Behav Brain Sci 2005;28(03):397-419, discussion 419-468

193 Sonuga-Barke EJ. Editorial: ADHD as a reinforcement disorder moving from general effects to identifying (six) specific models to test. J Child Psychol Psychiatry 2011;52(09):917-918

194 Tripp G, Wickens JR. Research review: dopamine transfer deficit: a neurobiological theory of altered reinforcement mechanisms in ADHD. J Child Psychol Psychiatry 2008;49(07):691-704

195 Plichta MM, Scheres A. Ventral-striatal responsiveness during reward anticipation in ADHD and its relation to trait impulsivity in the healthy population: a meta-analytic review of the fMRI literature. Neurosci Biobehav Rev 2014;38:125-134

196 Hauser TU, Iannaccone R, Ball J, et al. Role of the medial prefrontal cortex in impaired decision making in juvenile attention-deficit/hyperactivity disorder. JAMA Psychiatry 2014;71 (10):1165-1173

197 Scheres A, Milham MP, Knutson B, Castellanos FX. Ventral striatal hyporesponsiveness during reward anticipation in attention-deficit/hyperactivity disorder. Biol Psychiatry 2007;61(05):720-724

198 Aarts E, van Holstein M, Hoogman M, et al. Reward modulation of cognitive function in adult attention-deficit/hyperactivity disorder: a pilot study on the role of striatal dopamine. Behav Pharmacol 2015;26(1,2):227-240 
199 Baumeister S, Wolf I, Hohmann S, et al. The impact of successful learning of self-regulation on reward processing in children with ADHD using fMRI. Atten Defic Hyperact Disord 2019;11(01): 31-45

200 Baumeister S, Wolf I, Holz N, et al. Neurofeedback training effects on inhibitory brain activation in ADHD: a matter of learning? Neuroscience 2018;378:89-99

201 Rubia K, Halari R, Cubillo A, Mohammad AM, Brammer M, Taylor E. Methylphenidate normalises activation and functional connectivity deficits in attention and motivation networks in medication-naïve children with ADHD during a rewarded continuous performance task. Neuropharmacology 2009;57(7,8):640-652

202 Faraone SV, Larsson H. Genetics of attention deficit hyperactivity disorder. Mol Psychiatry 2019;24(04):562-575

203 Larsson H, Chang Z, D'Onofrio BM, Lichtenstein P. The heritability of clinically diagnosed attention deficit hyperactivity disorder across the lifespan. Psychol Med 2014;44(10):2223-2229

204 Sudre G, Choudhuri S, Szekely E, et al. Estimating the heritability of structural and functional brain connectivity in families affected by attention-deficit/hyperactivity disorder. JAMA Psychiatry 2017;74(01):76-84

205 Anokhin AP, Golosheykin S, Grant JD, Heath AC. Heritability of brain activity related to response inhibition: A longitudinal genetic study in adolescent twins. Int J Psychophysiol 2017; 115:112-124

206 Pappa I, Fedko IO, Mileva-Seitz VR, et al. Single nucleotide polymorphism heritability of behavior problems in childhood: genome-wide complex trait analysis. J Am Acad Child Adolesc Psychiatry 2015;54(09):737-744

207 Greven CU, Merwood A, van der Meer JM, Haworth CM, Rommelse N, Buitelaar JK. The opposite end of the attention deficit hyperactivity disorder continuum: genetic and environmental aetiologies of extremely low ADHD traits. J Child Psychol Psychiatry 2016;57(04):523-531

208 Anttila V, Bulik-Sullivan B, Finucane HK, et al; Brainstorm Consortium. Analysis of shared heritability in common disorders of the brain. Science 2018;360(6395):360

209 Taylor MJ, Martin J, Lu Y, et al. Association of genetic risk factors for psychiatric disorders and traits of these disorders in a swedish population twin sample. JAMA Psychiatry 2019;76 (03):280-289

210 Gizer IR, Ficks C, Waldman ID. Candidate gene studies of ADHD: a meta-analytic review. Hum Genet 2009;126(01):51-90

211 Wu J, Xiao H, Sun H, Zou L, Zhu LQ. Role of dopamine receptors in ADHD: a systematic meta-analysis. Mol Neurobiol 2012;45(03): 605-620

212 Anney RJ, Lasky-Su J, O'Dúshláine C, et al. Conduct disorder and ADHD: evaluation of conduct problems as a categorical and quantitative trait in the international multicentre ADHD genetics study. Am J Med Genet B Neuropsychiatr Genet 2008;147B (08):1369-1378

213 Franke B, Neale BM, Faraone SV. Genome-wide association studies in ADHD. Hum Genet 2009;126(01):13-50

214 Hinney A, Scherag A, Jarick I, et al; Psychiatric GWAS Consortium: ADHD subgroup. Genome-wide association study in German patients with attention deficit/hyperactivity disorder. Am J Med Genet B Neuropsychiatr Genet 2011;156B(08):888-897

215 Lasky-Su J, Neale BM, Franke B, et al. Genome-wide association scan of quantitative traits for attention deficit hyperactivity disorder identifies novel associations and confirms candidate gene associations. Am J Med Genet B Neuropsychiatr Genet 2008;147B(08):1345-1354

216 Mick E, Todorov A, Smalley S, et al. Family-based genome-wide association scan of attention-deficit/hyperactivity disorder.J Am Acad Child Adolesc Psychiatry 2010;49(09):898-905.e3

217 Neale BM, Lasky-Su J, Anney R, et al. Genome-wide association scan of attention deficit hyperactivity disorder. Am J Med Genet B Neuropsychiatr Genet 2008;147B(08):1337-1344
218 Neale BM, Medland S, Ripke S, et al; IMAGE II Consortium Group. Case-control genome-wide association study of attention-deficit/hyperactivity disorder. J Am Acad Child Adolesc Psychiatry 2010;49(09):906-920

219 Neale BM, Medland SE, Ripke S, et al; Psychiatric GWAS Consortium: ADHD Subgroup. Meta-analysis of genome-wide association studies of attention-deficit/hyperactivity disorder. J Am Acad Child Adolesc Psychiatry 2010;49(09):884-897

220 Sánchez-Mora C, Ramos-Quiroga JA, Bosch R, et al. Case-control genome-wide association study of persistent attention-deficit hyperactivity disorder identifies FBXO33 as a novel susceptibility gene for the disorder. Neuropsychopharmacology 2015;40 (04):915-926

221 Stergiakouli E, Hamshere M, Holmans P, et al; deCODE Genetics; Psychiatric GWAS Consortium. Investigating the contribution of common genetic variants to the risk and pathogenesis of ADHD. Am J Psychiatry 2012;169(02):186-194

222 van Hulzen KJE, Scholz CJ, Franke B, et al; PGC ADHD Working Group; PGC Bipolar Disorder Working Group. Genetic overlap between attention-deficit/hyperactivity disorder and bipolar disorder: evidence from genome-wide association study metaanalysis. Biol Psychiatry 2017;82(09):634-641

223 Yang L, Neale BM, Liu L, et al; Psychiatric GWAS Consortium: ADHD Subgroup. Polygenic transmission and complex neuro developmental network for attention deficit hyperactivity disorder: genome-wide association study of both common and rare variants. Am J Med Genet B Neuropsychiatr Genet 2013;162B(05):419-430

224 Zayats T, Athanasiu L, Sonderby I, et al. Genome-wide analysis of attention deficit hyperactivity disorder in Norway. PLoS One 2015;10(04):e0122501

225 Demontis D, Walters RK, Martin J, et al; ADHD Working Group of the Psychiatric Genomics Consortium (PGC); Early Lifecourse \& Genetic Epidemiology (EAGLE) Consortium; 23andMe Research Team. Discovery of the first genome-wide significant risk loci for attention deficit/hyperactivity disorder. Nat Genet 2019;51(01): 63-75

226 Canadian Attention Deficit Hyperactivity Disorder Resource Alliance (CADDRA). Canadian ADHD practice Guidelines. Fourth edition. 2018 Available at: https://www.caddra.ca/downloadguidelines. Accessed February 18, 2019

227 Pliszka S; AACAP Work Group on Quality Issues. Practice parameter for the assessment and treatment of children and adolescents with attention-deficit/hyperactivity disorder. J Am Acad Child Adolesc Psychiatry 2007;46(07):894-921

228 Taylor E, Döpfner M, Sergeant J, et al. European clinical guidelines for hyperkinetic disorder - first upgrade. Eur Child Adolesc Psychiatry 2004;13(Suppl 1):I7-I30

229 Döpfner M, Ise E, Breuer D, Rademacher C, Metternich-Kaizman TW, Schürmann S. Long-term course after adaptive multimodal treatment for children with ADHD: an 8-year follow-up. J Atten Disord 2016; (e-pub ahead of print) . Doi: 10.1177/ 1087054716659138

230 Geissler J, Jans T, Banaschewski T, et al. Individualised short-term therapy for adolescents impaired by attention-deficit/hyperactivity disorder despite previous routine care treatment (ESCAadol)-Study protocol of a randomised controlled trial within the consortium ESCAlife. Trials 2018;19(01):254

231 Coates J, Taylor JA, Sayal K. Parenting interventions for ADHD: a systematic literature review and meta-analysis. J Atten Disord 2015;19(10):831-843

232 Daley D, Van Der Oord S, Ferrin M, et al. Practitioner review: current best practice in the use of parent training and other behavioural interventions in the treatment of children and adolescents with attention deficit hyperactivity disorder. J Child Psychol Psychiatry 2018;59(09):932-947

233 Tarver J, Daley D, Sayal K. Beyond symptom control for attentiondeficit hyperactivity disorder (ADHD): what can parents do to improve outcomes? Child Care Health Dev 2015;41(01):1-14 
234 Robin AL. Family therapy for adolescents with ADHD. Child Adolesc Psychiatr Clin N Am 2014;23(04):747-756

235 DuPaul GJ, Gormley MJ, Laracy SD. School-based interventions for elementary school students with ADHD. Child Adolesc Psychiatr Clin N Am 2014;23(04):687-697

236 Moore DA, Richardson M, Gwernan-Jones R, et al. Non-pharmacological interventions for ADHD in school settings: an overarching synthesis of systematic reviews. J Atten Disord 2019;23 (03):220-233

237 Richardson M, Moore DA, Gwernan-Jones R, et al. Non-pharmacological interventions for attention-deficit/hyperactivity disorder (ADHD) delivered in school settings: systematic reviews of quantitative and qualitative research. Health Technol Assess 2015;19(45):1-470

238 Walitza S, Romanos M, Greenhill LL, Banaschewski T. AttentionDeficit/Hyperactivity Disorders. In: Gerlach M, Warnke A, Greenhill LL, eds. Psychiatric Drugs in Children and Adolescents. Wien: Springer; 2014:369-381

239 Walitza S, Gerlach M, Romanos M, Renner T. Psychostimulanzien und andere Arzneistoffe, die zur Behandlung der Aufmerksamkeitsdefizit-/Hyperaktivitätsstörung (ADHS) angewendet werden. In: Gerlach M, Mehler-Wex C, Walitza S, Warnke A, Wewetzer C, eds. Neuro-/Psychopharmaka im Kindes- und Jugendalter: Grundlagen und Therapie. Berlin, Heidelberg: Springer Berlin Heidelberg; 2016:289-331

240 The MTA Cooperative Group. Multimodal Treatment Study of Children with ADHD. A 14-month randomized clinical trial of treatment strategies for attention-deficit/hyperactivity disorder. Arch Gen Psychiatry 1999;56(12):1073-1086

241 MTA Cooperative Group. Moderators and mediators of treatment response for children with attention-deficit/hyperactivity disorder: the Multimodal Treatment Study of children with Attention-deficit/hyperactivity disorder. Arch Gen Psychiatry 1999;56(12):1088-1096

242 MTA Cooperative Group. National Institute of Mental Health Multimodal Treatment Study of ADHD follow-up: 24-month outcomes of treatment strategies for attention-deficit/hyperactivity disorder. Pediatrics 2004;113(04):754-761

243 Banaschewski T, Soutullo C, Lecendreux M, et al. Health-related quality of life and functional outcomes from a randomized, controlled study of lisdexamfetamine dimesylate in children and adolescents with attention deficit hyperactivity disorder. CNS Drugs 2013;27(10):829-840

244 Coghill DR, Banaschewski T, Lecendreux M, et al. Efficacy of lisdexamfetamine dimesylate throughout the day in children and adolescents with attention-deficit/hyperactivity disorder: results from a randomized, controlled trial. Eur Child Adolesc Psychiatry 2014;23(02):61-68

245 Heal DJ, Smith SL, Gosden J, Nutt DJ. Amphetamine, past and present-a pharmacological and clinical perspective. J Psychopharmacol 2013;27(06):479-496

246 Sallee F, Connor DF, Newcorn JH. A review of the rationale and clinical utilization of $\alpha 2$-adrenoceptor agonists for the treatment of attention-deficit/hyperactivity and related disorders. J Child Adolesc Psychopharmacol 2013;23(05):308-319

247 Storebø OJ, Ramstad E, Krogh HB, et al. Methylphenidate for children and adolescents with attention deficit hyperactivity disorder (ADHD). Cochrane Database Syst Rev 2015;(11): CD009885

248 Döpfner M, Ise E, Wolff Metternich-Kaizman T, Schürmann S, Rademacher C, Breuer D. Adaptive multimodal treatment for children with attention-deficit-/hyperactivity disorder: an 18 month follow-up. Child Psychiatry Hum Dev 2015;46(01):44-56

249 Daley D, van der Oord S, Ferrin M, et al; European ADHD Guidelines Group. Behavioral interventions in attention-deficit/hyperactivity disorder: a meta-analysis of randomized controlled trials across multiple outcome domains. J Am Acad Child Adolesc Psychiatry 2014;53(08):835-847, 847.e1-847.e5
250 Sonuga-Barke EJ, Brandeis D, Cortese S, et al; European ADHD Guidelines Group. Nonpharmacological interventions for ADHD: systematic review and meta-analyses of randomized controlled trials of dietary and psychological treatments. Am J Psychiatry 2013;170(03):275-289

251 Ding Q Li M, Zhu D. Is combined CBT therapy more effective than drug therapy alone for ADHD in children? A meta-analysis. Traditional Medicine and Modern Medicine 2018;01:21-26

252 Bikic A, Leckman JF, Christensen TO, Bilenberg N, Dalsgaard S. Attention and executive functions computer training for attention-deficit/hyperactivity disorder (ADHD): results from a randomized, controlled trial. Eur Child Adolesc Psychiatry 2018;27 (12):1563-1574

253 Cortese S, Ferrin M, Brandeis D, et al; European ADHD Guidelines Group (EAGG). Cognitive training for attention-deficit/hyperactivity disorder: meta-analysis of clinical and neuropsychological outcomes from randomized controlled trials. J Am Acad Child Adolesc Psychiatry 2015;54(03):164-174

254 Loo SK, McGough JJ, McCracken JT, Smalley SL. Parsing heterogeneity in attention-deficit hyperactivity disorder using EEG-based subgroups. J Child Psychol Psychiatry 2018;59(03):223-231

255 Cortese S, Ferrin M, Brandeis D, et al; European ADHD Guidelines Group (EAGG). Neurofeedback for attention-deficit/hyperactivity disorder: meta-analysis of clinical and neuropsychological outcomes from randomized controlled trials. J Am Acad Child Adolesc Psychiatry 2016;55(06):444-455

256 Zuberer A, Brandeis D, Drechsler R. Are treatment effects of neurofeedback training in children with ADHD related to the successful regulation of brain activity? A review on the learning of regulation of brain activity and a contribution to the discussion on specificity. Front Hum Neurosci 2015;9:135

257 Liechti MD, Maurizio S, Heinrich H, et al. First clinical trial of tomographic neurofeedback in attention-deficit/hyperactivity disorder: evaluation of voluntary cortical control. Clin Neurophysiol 2012;123(10):1989-2005

258 Rubia K. Cognitive neuroscience of attention deficit hyperactivity disorder (ADHD) and its clinical translation. Front Hum Neurosci 2018;12:100

259 Marx AM, Ehlis AC, Furdea A, et al. Near-infrared spectroscopy (NIRS) neurofeedback as a treatment for children with attention deficit hyperactivity disorder (ADHD)-a pilot study. Front Hum Neurosci 2015;8:1038

260 Doruk Camsari D, Kirkovski M, Croarkin PE. Therapeutic applications of noninvasive neuromodulation in children and adolescents. Psychiatr Clin North Am 2018;41(03):465-477

261 Lee JC, Kenney-Jung DL, Blacker CJ, Doruk Camsari D, Lewis CP. Transcranial direct current stimulation in child and adolescent psychiatric disorders. Child Adolesc Psychiatr Clin N Am 2019;28 (01):61-78

262 Rubio B, Boes AD, Laganiere S, Rotenberg A, Jeurissen D, PascualLeone A. Noninvasive brain stimulation in pediatric attentiondeficit hyperactivity disorder (ADHD): a review. J Child Neurol 2016;31(06):784-796

263 Westwood S, Radua J, Rubia K. Non-invasive brain stimulation as an alternative treatment for ADHD: a systematic review and meta-analysis. Brain Stimulation. Basic, Translational, and Clinical Research in Neuromodulation 2019;12:502

264 Cairncross M, Miller CJ. The effectiveness of mindfulness-based therapies for ADHD: a meta-analytic review. J Atten Disord 2016; (e-pub ahead of print) . Doi: 10.1177/1087054715625301

265 Cerrillo-Urbina AJ, García-Hermoso A, Sánchez-López M, PardoGuijarro MJ, Santos Gómez JL, Martínez-Vizcaíno V. The effects of physical exercise in children with attention deficit hyperactivity disorder: a systematic review and meta-analysis of randomized control trials. Child Care Health Dev 2015;41(06): 779-788

266 Evans S, Ling M, Hill B, Rinehart N, Austin D, Sciberras E. Systematic review of meditation-based interventions for 
children with ADHD. Eur Child Adolesc Psychiatry 2018;27(01): 9-27

267 Krisanaprakornkit T, Ngamjarus C, Witoonchart C, Piyavhatkul N. Meditation therapies for attention-deficit/hyperactivity disorder (ADHD). Cochrane Database Syst Rev 2010;(06):CD006507

268 S J, Arumugam N, Parasher RK. Effect of physical exercises on attention, motor skill and physical fitness in children with attention deficit hyperactivity disorder: a systematic review. Atten Defic Hyperact Disord 2019; 11(02):125-137

269 Hollis C, Falconer CJ, Martin JL, et al. Annual research review: digital health interventions for children and young people with mental health problems - a systematic and meta-review. J Child Psychol Psychiatry 2017;58(04):474-503

270 Powell L, Parker J, Harpin V. ADHD: is there an app for that? A suitability assessment of apps for the parents of children and young people with ADHD.JMIR Mhealth Uhealth 2017;5(10):e149

271 Kietglaiwansiri T, Chonchaiya W. Pattern of video game use in children with attention-deficit-hyperactivity disorder and typical development. Pediatr Int (Roma) 2018;60(06):523-528

272 Gau SS, Chang JP. Maternal parenting styles and mother-child relationship among adolescents with and without persistent attention-deficit/hyperactivity disorder. Res Dev Disabil 2013; 34(05):1581-1594

273 Steinhausen HC, Drechsler R, Foldenyi M, Imhof K, Brandeis D. Clinical course of attention-deficit/hyperactivity disorder from childhood toward early adolescence. J Am Acad Child Adolesc Psychiatry 2003;42(09):1085-1092

274 Sudre G, Mangalmurti A, Shaw P. Growing out of attention deficit hyperactivity disorder: Insights from the 'remitted' brain. Neurosci Biobehav Rev 2018;94:198-209
275 Agnew-Blais JC, Polanczyk GV, Danese A, Wertz J, Moffitt TE, Arseneault L. Evaluation of the persistence, remission, and emergence of attention-deficit/hyperactivity disorder in young adulthood. JAMA Psychiatry 2016;73(07):713-720

276 Caye A, Rocha TB, Anselmi L, et al. Attention-deficit/hyperactivity disorder trajectories from childhood to young adulthood: evidence from a birth cohort supporting a late-onset syndrome. JAMA Psychiatry 2016;73(07):705-712

277 Moffitt TE, Houts R, Asherson P, et al. Is adult ADHD a childhoodonset neurodevelopmental disorder? Evidence from a four-decade longitudinal cohort study. Am J Psychiatry 2015;172(10): 967-977

278 Cooper M, Hammerton G, Collishaw S, et al. Investigating lateonset ADHD: a population cohort investigation. J Child Psychol Psychiatry 2018;59(10):1105-1113

279 Sibley MH, Rohde LA, Swanson JM, et al; Multimodal Treatment Study of Children with ADHD (MTA) Cooperative Group. Lateonset ADHD reconsidered with comprehensive repeated assessments between ages 10 and 25. Am J Psychiatry 2018;175(02): 140-149

280 Bonvicini C, Faraone SV, Scassellati C. Common and specific genes and peripheral biomarkers in children and adults with attention-deficit/hyperactivity disorder. World J Biol Psychiatry 2018;19(02):80-100

281 Swanson JM, Arnold LE, Jensen PE, et al. Longterm outcomes in the Multimodal treatment study of children with ADHD (the MTA): From beginning to the End. In: Banaschewski T, Coghill D, Zuddas A, eds. Oxford Textbook of Attention Deficit Hyperactivity Disorder. Oxford: Oxford University Press; 2018: 315-332 